\title{
Zum Gebrauch des Duals und des Plurals im Juraksamojedischen
}

In Castréns Grammatik ( $\$ 220)$ lesen wir folgende Feststellung: "Das Samojedische hat drei Numeri: den Singular, Dual und Phral, von denen der Dual jedoch im Kamassinschen Dialekt ganz und gar fehlt und auch im Ostjaksamojedischen selten ist. In den nördlichen Dialekten I=Sprachenl kann zwar der Dual allgemein gebraucht werden, aber auch hier ist seine Deklination sehr unvollständig... Es zeigt sich deutlich, dass der Dual und Plural sich noch nicht vollständig in ihren einzelnen Casus haben entwickeln können. Von diesen ist in der Tat nur der Nominativ öfter in Gebrauch. In den übrigen Casus wird der Dual und Plural meist durch den Singular mit Hinzufügung eines Bestimmungswortes: zuei, viele, alle ersetzt.» Im folgenden Paragraphen (S. 109) stellt Castrén auch fest, diss das Zeichen des Duals im .Jurakischen ${ }^{*} k+$ Vokal ist ${ }^{1}$, im Tawgy kai $\sim$ gai, im Jenisseischen ${ }^{*} k u,{ }^{*} k v$, im Selkupischen $k^{2}$ Castrén berief sich auch auf das ostjakische Dualsuffix zan, gan $\sim$ yen. gen, wie auch auf das lappische Dualzeichen $g$. Es soll hier gleich bemerkt werden, dass das Element $n$ auch in Castríns waldjurakischen Aufzeichnungen vorkommt (Mat 301): poon$g a-h a(n)$, vgl. poonga 'Netz' und nach einigen sporadischen Belegen auch im Tundrajurakischen existiert: O śide juŕo-

${ }^{1}$ In Castréns Texten auch gui (vgl. FUF XXXVIII, 160), in seinen waldjurakischen Aufzeichnungen $h \bar{a}<{ }^{*} k a+{ }^{*} j \varepsilon(i)$. Das Element ${ }^{*} j \varepsilon(i)$ kann als Pluralzeichen identifiziert werden (vgl. A. J. Joki CSIFU I 225).

${ }^{2}$ Im Baicha-Dialekt auch kai, vgl. (Mat 152) maat Zelt: Nom. Dual maat-kai. 


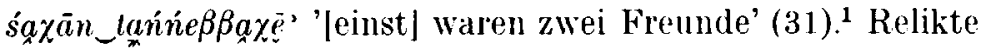
des Dualzeichens können auch im Kamassischen nachgewiesen werden: "Das alte Dualsuffix kommt in der Form ka $\alpha_{a} \bar{a}-$

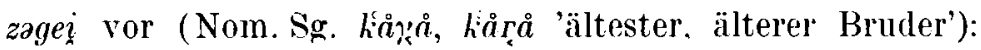

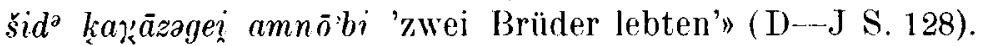
Vgl. noch šidaga nukkīna az bi $i$ 'zu zweien baten sie um eine Frau' (ebd. S. 90).

Das vokalische Element des Dualzeichens hängt im Jurakischen vom unmittelbar vorangehenden Vokal ab. Aus Castréns Deklinationsparadigmen zitiere ich folgende Angaben: muda 'Hand': Nom. Dual nudaha; narne 'Krähe': warnehe; habi 'Diener': habihi'; jano 'Boot': yanoho; tumju 'Ofen': 'umjuhu (vol. Gr. \$244, 245). Die Dualformen der Verben weisen keinen solchen Abwechselungsreichtum in der Grammatik auf, besonders deshalb, weil das Inalsuffix meist bei den indikativischen Dualformen der 3 . Person an den

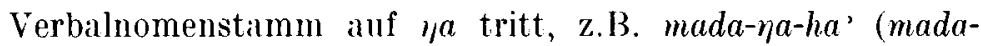
'schneiden', §494), aber hōny-hy' (hōny- 'schlafen', § 496). Aus den Texten sind aber auch Formen wie äedalihi 'sie fahren' (253), janguhu 'sie sind nicht da' (231) usw. bekannt. Die Belege aus Lehtisalos Texten zeigen im wesentlichen dieselbe Erscheinung. ${ }^{2}$

Im Jahre 1941 erschien Paavo Ravilas wichtige Studie "Über die Verwendung der Numeruszeichen in den uralischen Sprachen" (FUF XXVII, 1-136). Ravila hatte auch die zur Verfügung stehenden samojedischen Texte eingehend studiert. ${ }^{3}$ Die Resultate seiner Forschungen hat er fürs Sa-

${ }^{1}$ Zum Element $n$ vgl. auch K. J. Majtinskaja: Zur Frage des Duals in den uralischen Sprachen. Sowjetische Finnisch-Ugrische Sprachwissenschaft IV (1968) S. 153-163.

2 Interessant ist die Erklärung, die Bo Wickman für den o-Laut der zweiten Silbe von noho $\left(<{ }^{*}\right.$ noka $)$ 'Polarfuchs' gibt: "The $o$ of the second syllable in this word is probably to be accounted for by the preceding $h$, this consonant being generally followed by the same vowel as that of the preceding syllable" (vgl. The Form of the Object ... 89). Diese Feststellung ist keine Regel, denn es gibt Ausnahmen (vgl. Joki: FUF XXXII Anz. 24), es existiert aber als Te n de n z im Jurakischen. Vgl. noch den Vokalismus des Koaffixes ${ }^{*} k$.

${ }^{3}$ Samojedische Volksdichtung. Gesammelt von M. A. Castrén. Her- 
mojedische wie folgt zusammengefilsst: "duf Grund des zur Verfügung stehenden Materials ist es unmöglich, oin ganz klares Bild von der Vertretung in den simojedischen Sprachen zu gewinnen. Es scheint jedoch, als wäre der Singular neben dem Dual, dem Plıral und mit Hilfe des Wortes für 'zwei' gebildeten Ausdrücken verhältnismässig läıfìn, z.В. samJ (Castrín-Lehtisalo... s. 73) äemda udamda madasi uanoltãda 'seine Füsse. Hände abschneidend schreckte a' ihn zu gehen', (ib. S. 140) aeda nümda daerï 'seine Füsse' kamen in den Himmel'. Für den Gebrauch des Wortes 'halb' habe ich keine Belege gefunden. Wenn nur ron dem einen Vertreter eines Palares die Rede ist, wird der Ausdruck 'der' eine -- der andere' angewandt, z.B. (ib. S. 121) tjürumda jinjemda ob udahanda njamãda, njāei udahanda hanamda

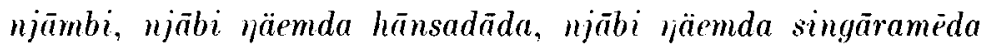
'seine Treibstange und seinen Riemen nahm er in seine eine Hand, in der anderen Hand hält ar seinen Schlitten, seinen einen Fuss hält er als Kufe, seinen anderen Fuss hält or als Bremse'" (a.a.O. 21 ).

Im Jahre 1947 erschien Toivo Lehtisalos an Ort und stelle ilufgezeichnetes, überaus wertvolles und reiches juraksimojedisches Volksdichtungsmaterial und im Jahre 1956 sein juraksamojedisches Wörterbuch. ${ }^{1}$ Dieses neuere Material bestätigt Ravilas Feststellungen für das samojedische in allem; auch bestätigt es mit ergänzenden Belegen das Ergebnis der Forschungen Ravilas. dass der Gebrauch des Duals im Juriksamojedischen im wesentlichen mit dem Gebrauch des Duals übereinstimmt, der aus den obugrischen und den lappischen Sprachen nachgewiesen wurde (a.a.O. S. 54, 55-57.).

In Lehtisalos Texten finden sich nur vereinzelte Belege dafür, dass der Singular der paarigen Körperteile beide Glie-

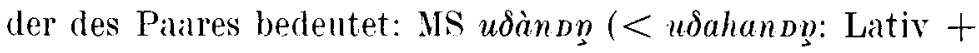

ausgegeben von T. Lehtisalo MSFOu LXXXIII 1940; J. Budenz: Adalékok a jurák-szamojéd nyelv ismeretéhez (Beiträge zur Kenntnis der juraksamojedischen Sprache) NyK XXII, 81-112.

1 Juraksamojedische Volksdichtung (MSFOu XC, XII - 615 S.); Juraksamojedisches Wörterbuch, CIX + 601 S. Abgekürzt Seitenzahl bzw. Wh + Seitenzahl. 
Possessirsuffix Sg. 3) tōrkkam' mannce 'a 'auf seinen Finger [eig. die Verzweigung seiner Hand] blickt er' (267); PD $t a \bar{\delta}{ }^{p}$ ńésénty sè $\beta$ mannèion 'er betrachtete dann die Augen seiner Intter' (163; das i-Element des Prädikats deutet auf ein pluralisches Objekt). ${ }^{1}$

Aus dem Textzusammenhang wird deutlich, dass der Singular des paarigen Körperteils nur ein Glied des Paars be-

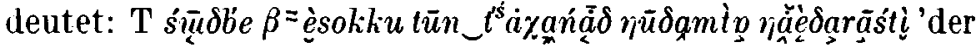
Riesenunhold-Alte reckt hinter dem Feuer öfters seine Hand

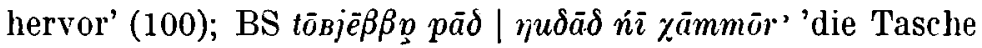
ilus gegerbtem Leder | fällt nicht aus der Hand' (363); Kan

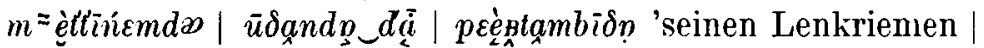
um seine Hand | schlingt er' (218). ${ }^{2}$

Anhand der jurakischen Texte Lehtisalos und der kamassischen von Donner-Joki wie auch auf Grund der sporadischen Belege aus dem selkupischen Wörterbuch von Prokofjev-Erdélyi kann festgestellt werden, dass Ausdrücke vom ungarischen Typ félkéz 'halbe [d.h. eine] Hand', félláb 'halber [d.h. ein] Fuss', félszem 'halbes [d.h. das eine] Auge' auch im Samojedischen nicht fehlen. In diesen Ausdrücken hängt das Wort 'halb' auch etymologisch mit dem ungarischen Wort fél, fi. puoli usw. zusimmen. Ein Zitat aus einem

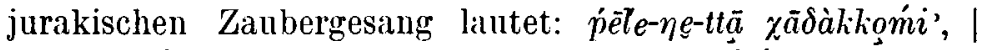

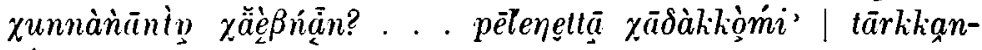
$\dot{b}^{\dot{*} \bar{e} r}$ ' pujje nine 'Mein einbeiniges Grossmütterchen, | wohin gingst du? | . . mein einbeiniges Grossmütterchen | auf der tärkian $\dot{b}^{4} \bar{e}$-Landzunge' (Mat 439). ${ }^{3}$ Vgl. noch kam. (D-J) p'êl simābb kaịlaua 'bi 'das eine Auge schloss er aber' (99). Im Selkupischen wird die mit rem Suffix $l$ gebildete Ableitung

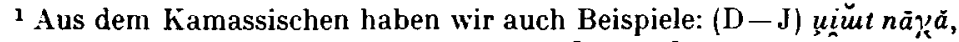

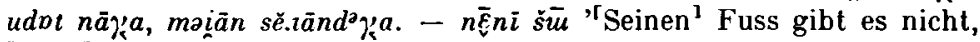
' seine $^{\mathrm{l}}$ Hand gibt es nicht, kriecht auf den Berg. - Das Lauffeuer' (85); "tan siman tezerrladan" "Deine Augen werden sie heilen" (99).

${ }^{2}$ Auch im Kamassischen: (D - J) udam mol'em 'die Hand geben'; auch im Ungarischen analog: kezet ad 'die Hand geben', kezébe seszi a kenyeret 'das Brot in die Hand nehmen' usw.

3 In einigen Tundra-Dialekten des Jurakischen hat das Wort (Wb 376) pēllè, pêlle $\left(<{ }^{*}\right.$ pèl $\left.+j \varepsilon\right)$ 'Hälfte, Stück' auch ein Verb-Gegenstück: O ṕp̄l-, Tे pélla- 'die Hälfte wegnehmen'. 
als Attribut der paarigen Körperteile gebraucht: (Prok.Erd.) peläl sajisä onannimpak 'mit einem Auge sehe ich', peläl utisä orqilniti 'mit einer Hand fasste er es'.

Während ich im Jurakischen nur ein einziges Beispiel für das Wort *pèl 'halb' als Attribut für den Namen eines paarigen Körperteils gefunden habe, kann ich mehrere Belege aus den Texten und aus dem Wörterbuch von Lehtisalo anführen, Zusammensetzungen (attributive Konstruktionen), in denen das eine Glied des paarigen Körperteils mit dem

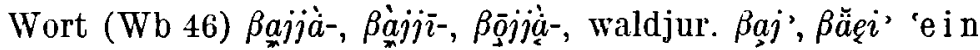
(von paarigen Körperteilen des Menschen und der Tiere)'

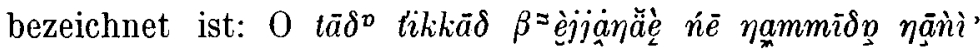
mattōrjē $\bar{d} p$ 'dann schnitt das Einbein-Weib wieder seine Brüste $a b$ ' (104). Im Band "Samojedische Sprachmaterialien" von Castrén und Lehtisalo ${ }^{1}$ kommt der Ausdruck 'Ein-

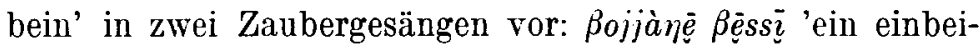

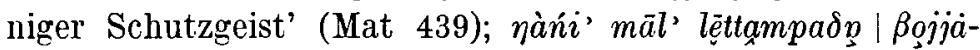
$\eta \ddot{a ̈ e ́ n i ' ~ s i u ́ u a r t e ~ ' w i e d e r ~ d e r ~ a l l e ~ h u ̈ t e n d e \mid e i n b e i n i g e r ~ P f e i-~}$ fer' (ebd. 444). Zu beachten sind auch die folgenden Beispiele

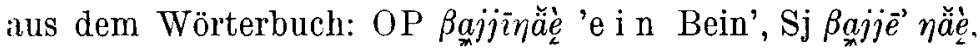

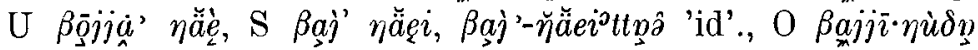

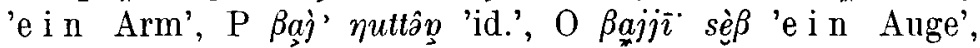
$\mathrm{Nj}$ S $\beta a j$ zăèm 'id'. Der Kehlkopfverschluss am Ende des Wortes mit der Bedeutung e in ersetzt das abgeschliffene Possessivsuffix.

In Lehtisalos Texten - - ebenso wie in denen Castréns (vgl. Ravila a.a.O. S. 21) - drückt das eine Glied der paarigen Körperteile nach zahlreichen Belegen das Attribut 'ein',

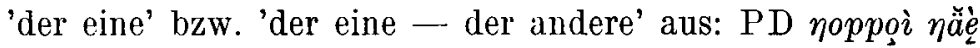
ńînne $\dot{p} \dot{a} \beta \beta \bar{e} \delta \partial \hat{~}$ 'mit einem Bein hat er angefangen [Ski zu

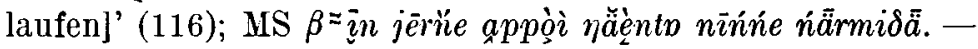
marrałGà 'Es rötet sich mitten im Sumpf auf einem Bein.

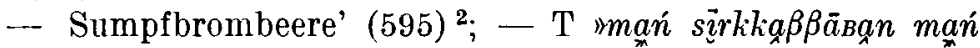
śüramba

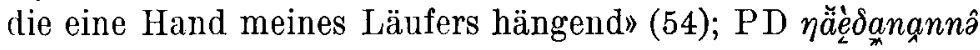

1 MSFOu 122, (1960), 468 S. Abgekürzt: Mat

2 Auch im Selkupischen (C) oker hai 'einäugig' [eig. ein-Auge] (Mat 81). 


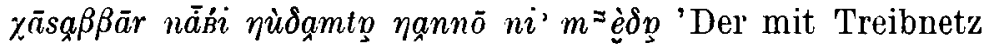
fischende Mann legte seine eine Hand auf das Boot' (122);

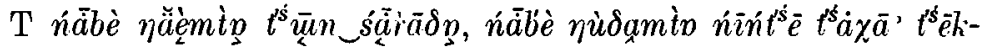
$k a l \eta \bar{a} \delta \underline{y}$ 'sein eines Bein band er hinauf, seine eine Hand hängte er hinter seinen Gürtel' (53). ${ }^{1}$ Handelt es sich nicht um ein zusammenhängendes Paar, so drücken dualisches Prädikat und Possessivsuffix die beiden Handelnden aus: T

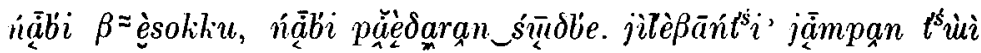

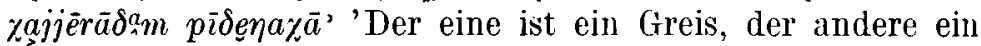
Waldriese. Zeit ihres Lebens streiten sie um die Sonne oben' (91). - - In einem Beispiel nimmt nur der zweite Vertreter der nicht zusammenhängenden beiden Gegenstände das

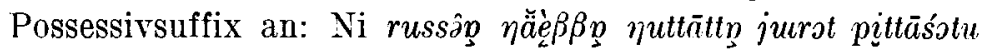
'den Kopf und die Hände des Russen steckte er in das Fett' (85-86).

In Lehtisalos Texten wird das dualische Subjekt am häufigsten durch die Verbindung des numeralischen Attributs sĩd'e 'zwei' und des Nomens im Singular ausgedrückt. Das Prädikat trägt konsequent das Dualsuffix oder — seltener

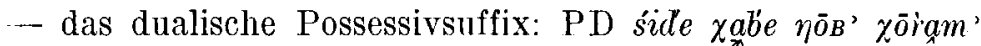

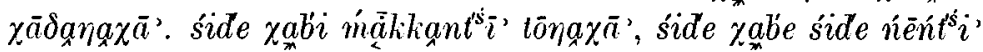

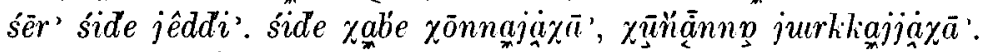

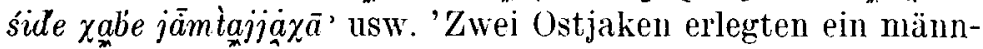
liches Renntier. Zwei Ostjaken kamen nach Hause. Zwei Ostjaken hatten ihren zwei Fraulen gemäss zwei Töpfe. Zwei Ostjaken gingen schlafen, am Morgen standen sie auf. Zwei Ostjaken begaben sich auf die Umzugsreise' (167) usw. --. In Lehtisalos Texten beginnt die erste Ursprungssage mit dem

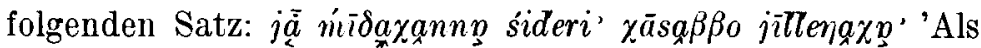
die Erde geschaffen wurde, lebten nur zwei Männer' (1). In den folgenden Sätzen drücken die dualistischen Prädikate und die Possessivsuffixe an den Zustandsbestimmungen aus, dass das Geschehen zwei P'ersonen hat, die zwei Männer

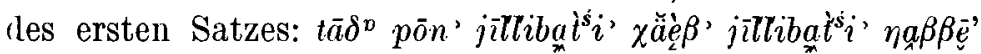

${ }^{1} \mathrm{Vgl}$. kam. (D-J) digoti simat poktla sa'mobi, digoti ṕulebi, àmi simat poktla samobi, ami simat poktla sa'mobi 'Dann platzte ihr Auge entzwei. Danach blies sie, ihr anderes Auge platzte, ihr anderes Auge platzte' (197). 


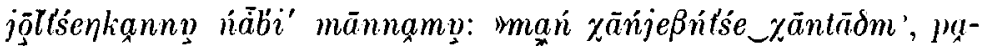

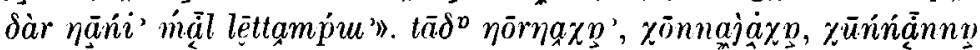

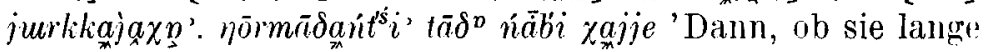
oder kurze Zeit lebten, sagte irgendwann der eine: "Ich gehe jagen, dı wieder hüte das Zelt!» Dann assen sie, legten sich schlafen, am Morgen standen sie auf. Nachdem sie gegessen hatten, begab sich dann der eine (fort)' (ebd.).

Bemerkenswert sind die Belege, in denen ein Glied des zusammenhängenden Paares - in der Funktion eines Komitativs -.- durch eine postpositionale Konstruktion bezeichnet wird.

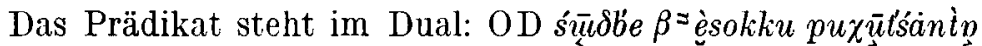

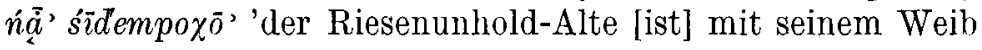
zu zweien' (106; - das nominale Prädikat ist das Numerale

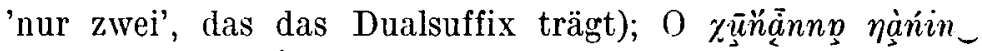

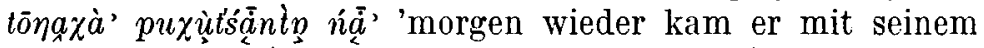

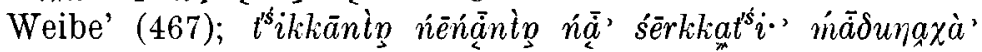
'dann wohnt er mit seiner Schwester in verschiedenen Zelten' (439). - In einer Aufforderung drückt das Possessivsuffix des Duals die Dualität des Prädikats aus: 0 "padari:

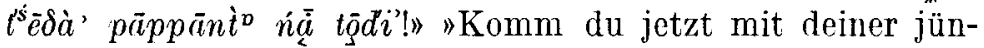

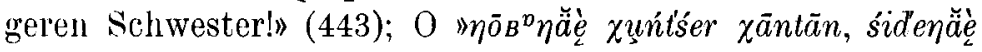

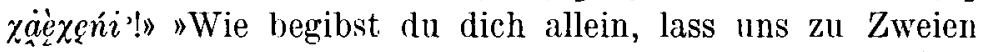

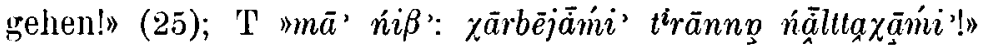
"er sagte nämlich: Lasst uns mit der Faust unsere grosse Lärche durchbohren!» (92). In den beiden letzteren Beispielen ist das Element $\chi e, \chi^{\bar{a}}$ kein Dualzeichen, sondern ein desideratives Ableitungssuffix: ${ }^{*} k \varepsilon$ bzw. ${ }^{*} k a+j \varepsilon(i)$ (vgl. FUF XXXVIII, 210-213).

Vor dem Namen paariger Körperteile erscheint das Wort

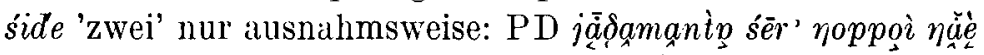

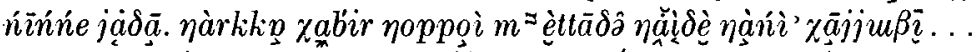

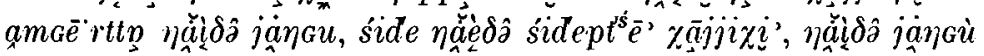
'nach Art seines Skilaufens läuft er mit einem Bein. Das von dem grossen Ostjaken behaltene eine Bein wieder ist (zurück-) geblieben ... kein Bein ist (da), zwei Beine, beide (Beine) blieben. Beine gibt es nicht' (117).

Ravila macht auf die Eigentümlichkeit aufmerksam (a.a.o. S. 160), dass der Dual des Nomens im Samojedischen auffal- 
lend selten allein gebraucht wird. Aus Castréns Texten zitiert er insgesamt drei Beispiele, auch in diesen Zitaten kommt das Wort atsekehe 'zwei Knaben' vor, in dem einen als Anrede, in dem zweiten als Subjekt des Satzes und im dritten als Nomen possessoris einer possessiven Konstruktion (S. 186, 252, 188). Auch der folgende Satz verdient Beachtung: meäli meakana | sideri nienets', | ōleri nieh. | habihi øäeuähä 'in dem grossen Zelt [fig. etym.] / sind nur zwei Männer, | ein einziges Weib, | Ostjaken waren es' (290). Der letzte Satz gehört als nominales Prädikat zum Subjekt 'zwei Männer'. — Aus Lehtisalos Texten können wir auch nur einzelne Belege zitie-

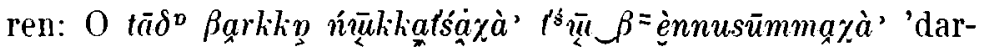
auf zogen sich die Bärenjungen aufrecht' (151, vgl. 156); OD

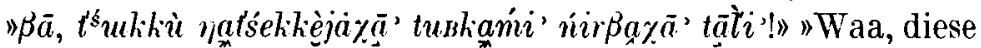
Kinder mögen nicht meine Axt stehlen!’ (107; im Prädikat wird das Dualzeichen mit dem Verbalnomen [auf $r+\beta a$ ] des verneinenden Verbs verbunden). … Ziemlich kompliziert

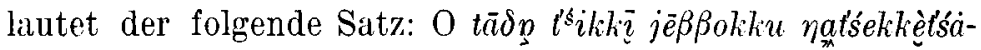

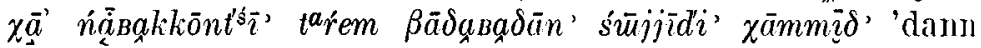
fielen diesen verwaisten Zwillings-Kindlein, während ihre ältere Schwester sie so aufzog, die Nabel ab' (456). Das Subjekt des Satzes ist - nach dem lheutigen Sprachgefühl das Wort $s \bar{u} j \bar{j} \bar{d} i$, 'Nabel', in dem dis dualische Possessivsuffix der 3. Person an den Pluralstamm tritt. Dieses Wort hat auch die Funktion eines Nomen possessi. Das Nomen possessoris nat'sekkètśa $\chi \bar{a}^{\prime}$ steht im Dual. Das Prädikat ist die dem Pluralstamm des Subjektes (siūjoj-) entsprechende Pluralform: $\chi \bar{a} m m \bar{\imath} \delta^{\prime}\left(<\chi \bar{a} m m \bar{\imath} \delta u^{\prime}\right)$.

Ostjakische Konstruktionen rom Typ imenar ikenan olla$\eta ә n$ 'eine Alte und ein Mann leben' (vol. Ravila a.a.O. S. 50, 56) können auch aus dem Juraksamojedischen nachgewiesen werden. Die Zahl der Belege ist gering. Das Dualzeichen bedeutet, wie in den obugrischen Sprachen, keinen Numerus, sondern die Zusammengehörigkeit der beiden Subjekte (vgl.

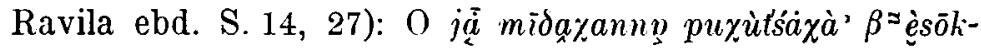

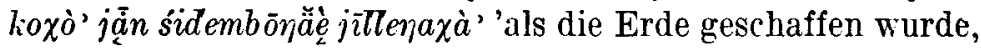
lebten eine Alte und ein Alter ganz allein zu zweien' (38),

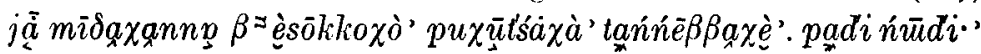




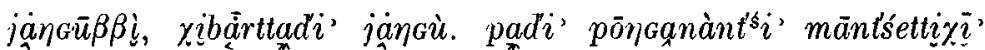
'Als die Erde geschaffen wurde, gab es einen alten Mann und eine Alte. Sie hatten keinen Sohn, niemanden haben sie. Untereinander sagen sie' (9). Die Dualität wird anch in diesen Sätzen durch die im Dual stehenden Prädikate und die dualischen Possessivsuffixe ausgedrückt. Vol. noch o $\beta=\grave{e s s o k k o \chi 0^{\prime}}$

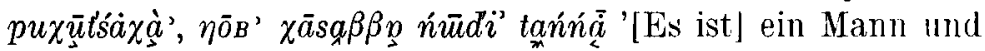
ein Weib, sie haben einen Sohn' (18). Das einzige jurak. Beispiel für den sog. elliptischen Dual (L 111: nis̉ajuttp nị̀ ' 'vor ihre. Eltern') führt T. Mikola an (Nyelvészeti Dolgozatok 85. Szeged 1969). Vgl. Ravila a.a.O. S. 22 ff.

Ein Nomen im Dual hat das Attribut sizde 'zwei' nur aus-

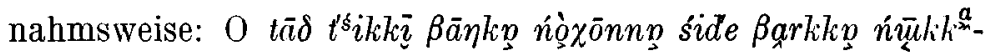

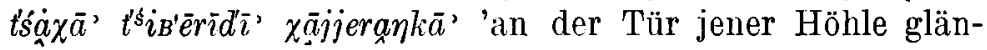
zen nur die Zähne von zwei Bärenjungen' (151). Das Nomen possessoris in der possessiven Fügung ist eine Dualform mit dem Attribut síde. Das Nomen possessi, das Subjekt des Satzes, trägt das dualische Possessivsuffix. - In einem Beleg aus dem PD-Dialekt fällt das passivische Prädikat im

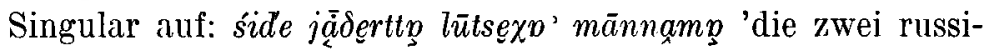
schen Schmiede sagten' (123).

In Lehtisalos Texten kommen Konstruktionen vor, in denen das Attribut sid'e 'zwei' mit einem Nomen verbunden ist, das mit dem Ableitungssuffix ${ }^{*} s a \sim{ }^{*} s \varepsilon$ gebildet ist und

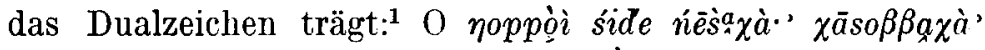

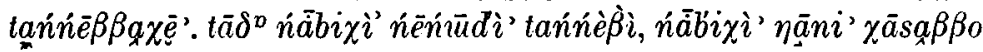

1 Dieses Ableitungssuffix uralischen Ursprungs bezeichnet Zusammengehörigkeit: (C) njaas 'Vetter' (Mat 283); jän goj ninje | njār piebes ( pieves) 'auf dem Landrücken [sind] drei Brüder' (1); - 0 já

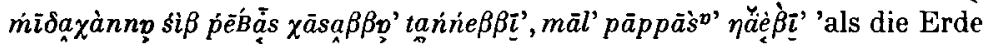
geschaffen wurde, waren sieben Männer-Gebrüder, alle waren Brüder'

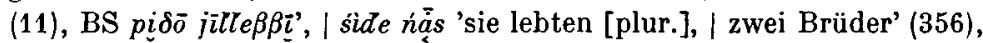
Vgl. noch die Angaben des Wb. (299). - Aus dem Ableitungssuffix hat sich im Selkupischen (Gr. $\$ 271$, Mat S. 240) und im Kamassischen $(D-J \$ 24)$ ein Kasussuffix des Instr.-Komit. entwickelt. Im Kamassischen tritt das Element $s e \sim z e$ in der possessiven Deklination an den Nominativ mit dem Possessivsuffix: $u d a-m-z e$ 'mit meiner Hand', uda-l-ze 'mit deiner Hand', utāce (<utā-t-se) 'mit seiner Hand' (vgl. D-J S. 140). 


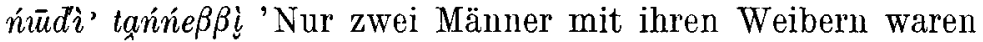
vorhanden. Dann hatten die einen von ihnen eine Tochter, die anderen wieder einen Sohn' (6; das Dualzeichen wird höchst selten mit einem Pronomen verbunden, in diesem Fall bedeutet die Form ńäbixi eigentlich 'das eine Ehepaar' - 'das andere Ehepaar'). - Der folgende Passus aus einem obdorskischen Text veranschaulicht den Gebrauch des Dualzeichens und der dualischen Personalsuffixe, wie auch des

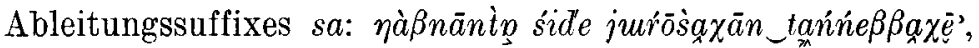

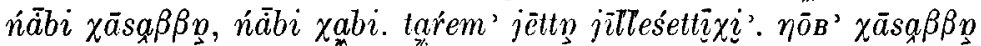

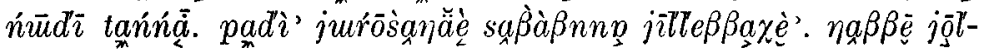
t'senkannp pad' ${ }^{\prime} \chi \bar{a} \eta \bar{a} \chi \grave{a}^{\prime}$ ' Einst waren zwei Freunde, der eine ein Samojede, der andere ein Ostjake. So gerade lebten sie. Jeder von ihmen hatte einen Sohn, sie lebten als Freunde gut. Irgendwann starben sie [die Väter]' (31).

Der syrjänische Ausdruck luna voi 'Nacht und Tag' (eig. 'mit dem Tag versehene Nacht') und der wogulische Ausdruck ji katel 'id.' (vgl. Rarila a.a.O. 43) haben auch im Jurakischen Entsprechungen. In Lehtisalos Texten kommen häufig Konstruktionen wie 'mit Tag versehene Nacht' und 'mit Nacht versehener Tag' vor, in denen an das erste Glied

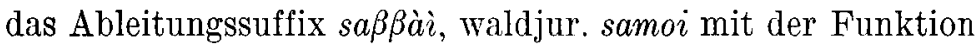

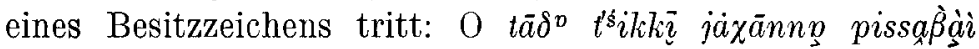

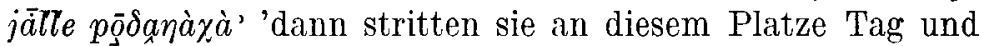

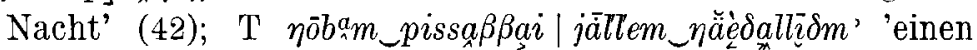
Tag und eine Nacht fahre ich' (375); MS ñ $\dot{a ̆}^{\prime}{ }^{\prime} j \bar{a} l l e m_{\smile \text { Bis- }}$ $s a \beta \beta \beta \ddot{a} e ̨ i \mid j a \bar{a} \delta \bar{a} n i$ ' 'drei Tage und Nächte wanderten wir [Du.]' (552). ${ }^{1}$ Es gibt auch dafür Beispiele, dass die Bedeutung 'mit

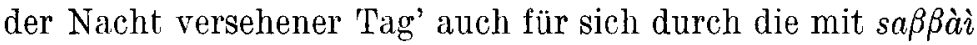
gebildete Ableitung des Wortes 'Nacht' ausgedrückt wird:

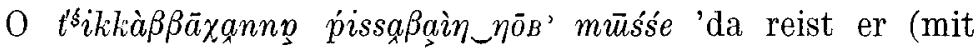
seinem Zelt) Tag und Nacht wnunterbrochen' (445). Vgl.

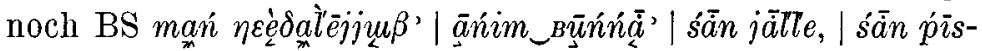

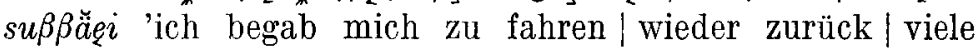
Tage, | viele Tage und Nächte' (367); MB śą $\bar{a} n$ jălle|jāil-

1 Zum sonstigen Gebrauch des Ableitungssuffixes im Jurakischen. Selkupischen und Kamassischen vgl. ALH IX, 86-89. 


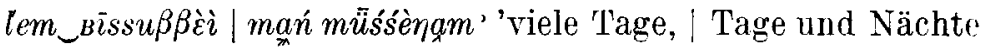
| treibe ich | meinen Rentierzug' (Mat 383). ${ }^{1}$

Für den Dual der Namen der paarigen Körperteile gibt es kaum Belege. In einem Frauennamen aus dem PD-Dialekt erscheint der Dual des Wortes für 'Auge': t'skkānty lint'serme säęêok néejjä pin' sannaptaì' 'dann sprang das Weib Rauschbeer-Auge hinaus' (166). ${ }^{2}$ In der OD- und der PDMundart drückt das an die Singularform tretende Possessivsuffix des Duals die Dualität aus: OD tū jālltem' mannèt'śe

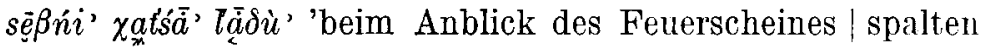
meine Augen beinahe auseinander' (192); 0 mièptá', sèprì' mannēkkar'!" "Bitte, sieh doch mal meine Augen an!" (163).

Tiernamen werden im Jurakischen im Singular gebraucht (vgl. Fokos-Fuchs: FUF XXIV, 299) und haben keine Dualform in den Texten. Eine Ausnahme bildet der Name des zahmen Rentiers, für dessen Dualform es in Castréns und Lehtisalos Texten zahlreiche Belege gibt. Es fällt auf, dass der Dual des Rentiers in manchen Fällen die Attribute 'hundert', 'viel' usw. hat, also ein Attribut, das Pluralität bedeutet. Die Erklärung dieser eigenartigen Ausdrücke finden wir in Lehtisalos Werk "Die Renntierzucht bei den Juraksamojeden" (Oslo 1932): "Wenn man die Herde an einen anderen Ort bringt, geschieht dies z.B. auf folgende Weise. Ein Samojede fäbrt voran und hat hinter dem Schlitten ein oder zwei abgerichtete Renntiere angebunden, denen zuerst die Gespannkameraden und dann andere Renntipre frei in langer Reihe $\mathrm{je} z \mathrm{wei}$ nebeneinander folgen... Die Lastschlitten werden dann zu Argischen (Karawanen) aneinander gespannt, die gewöhnlich die Weiber führen. Hinter dem letzten Argisch trabt langsam die Herde in schmaler Reihe je zwei Renntiere nebeneinander und zuletzt fährt der Treiber, der die Aufsicht über die Herde. hat ..." (S. 98-99) ${ }^{3}$. Die Attribute 'hundert', 'viel' usw.

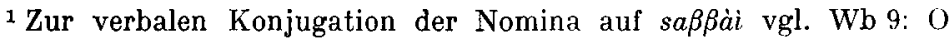

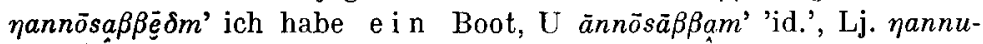
sāmmǎ̀̀ 'id'.

${ }^{2}$ Der Dual des Wortes sai 'Auge' ist im Baicha-Dialekt im Selkupischen sajog. In der possessiven Deklination 1. Sg. -gem, 3. -get (Mat 151).

${ }^{3}$ Sperrungen von mir. I.N.-S. 
beziehen sich also auf die durch den Dual ausgedrückten $\mathrm{R}$ e $\mathrm{n}$ t i e r p a a $\mathrm{r}$ e, solche Ausdrücke bedeuten also eigentlich 'hundert (viel usw.) Rentierpaare': (C) "jurk tehä tatam» "Hundert Rentiere gebe ich" (178); vjurmean|tehä kānal" "Etwa hundert Rentierpaare bringe!»; müudanda te'äh $\mid j w$ mahahë̈na 'die Rentiere ihrer Karawane sind|hundert Krummrücken' (223). Im Wort te'äh ersetzt der Kehlkopfverschluss das $k$-Element des Dualzeichens. Wenn das Auslaut-h - wie auch in anderen Fällen - das Zeichen des stimmlosen $i$ oder $i$ ist, so können wir es für wahrscheinlich halten, dass das Dualzeichen auch in diesem Wort in seiner volleren Form auftritt: 'äh <käi. Vgl. noch S. 254.

In einem Beleg aus Lehtisalos Texten ist der Nominativ Dual des Wortes für 'Rentier' ein unbezeichnetes objekt

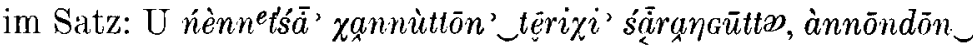

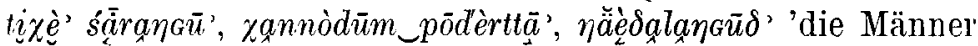
binden die Schlittenrentiere, binden die Bootrentiere, spannen die Schlitten an, fahren ab' (Mat 367), vgl. noch ' $\mathrm{T}$

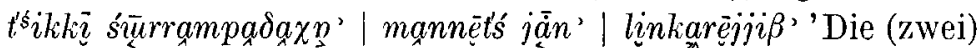
Läufer | als ich (sie) sah, in der Erde [Lativ] | versteckte ich mich' (376).

Ohne Zweifel ist das mit dem Dualzeichen versehene Prädikat das wichtigste Mittel zur Bezeichnung der Dualität. Auf das dualische Objekt weist das im Prädikat erscheinende Element (C) haju, (L) xajju hin. Das Possessivsuffix am Prädikat drückt die Person des Subjekts aus. Das Element haju, qajiu ist auch in den Namen des Objekts eingedrungen, ja in beschränktem Masse - wie wir noch sehen werden -- auch in den Namen des Subjekts. Es ist wahrscheinlich, dass das Element haju aus der Verbindung von $* k a+j \varepsilon+\beta$ (Dualund Pluralzeichen und dem Ableitungssuffix $* \beta$ ) entstanden ist und dass das Element $j u(j u)$ mit dem Element (C) $j u-m$, (L) ju-m usw. 'eine von zwei zusammengehörenden Personen oder Dinge' zusammenhängt (vgl. ALH X, 87). ${ }^{1}$

${ }^{1}$ In Castréns Paradigmen weist im Tawgy kai $\sim$ gai (Gr. \$422) auf den dualischen Besitz und kei gei (\$514) auf das dualische Objekt. Im Jenisseischen ist das entsprechende Zeichen $k u \sim h o \sim h u \sim h o$ (\$289), bzw. hu $(\$ 531)$. 
Aus vereinzelten Daten kann man schliessen, dass im Juraksamojedischen ursprünglich die Verbindung des Wortes śide 'zwei' und der Nominativ bzw. die Akkusativform des singularischen Nomens das Objekt im Dual ausgedrückt hat, und dass das Dualzeichen *kai im Prädikat ohne das Element $u$ erschienen ist: (C) "sid'e atsekim | amdanga-haj-ni» "Zwei Knaben | wir essen» (186). Auch die Variante des Prädikats amdangahajuni hat Castrén in demselben Satz aufgezeichnet. In einigen Fällen ist bei Lehtisalo nur das Dualzeichen im Prädi-

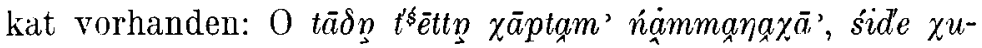
rūmmim' $\chi \bar{a} n n a \eta \eta_{\alpha} \alpha \grave{a}$ ' 'dann fingen sie [Du.] vier Rentierochsen ein, zwei Warenschlitten brachten sie fort' (462). Das dualische Objekt kanm auch durch das Possessivsuffix aus-

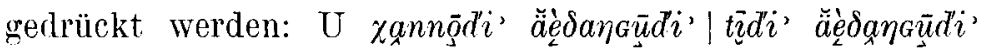
'[sie] spannen den Schlitten aus, lassen die Rentiere los' (Mat 366). Das Possessivsuffix am Prädikat drückt auch die Dualität des Subjekts aus.

Auf das dualische Objekt, das durch sid'e und die Singularform des Nomens ausgedrückt wird, weist in den Texten im allgemeinen das Prädikat, das ein Element haju, zaju enthält, hin: (C) side teamde ! äedarangäjudeh 'seine zwei Renntiere / liess er gehen' (76, vgl. 77); -- (L) OD side lè 'morōk-

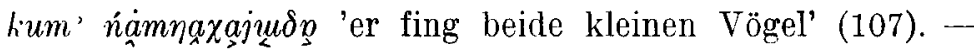
Sehr selten drückt der mit dem Dualzeichen versehene Nominativ das dualische Objekt aus: $O t \bar{a} \delta^{p}$ pin' tarppara-

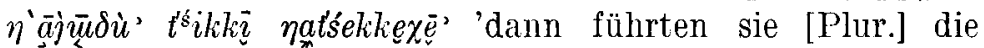
(zwei) Kinder hinaus' (7). Das folgende Zitat ist auch interessant, wo das Subjekt mit dem Dualzeichen versehen ist, und im nominalen Prädikat das Element $\chi u \ddot{j} \bar{u}$ mit dem Possessivsuffix des 1.P. Dual ausdrückt, dass es sich $1 \mathrm{~m}$

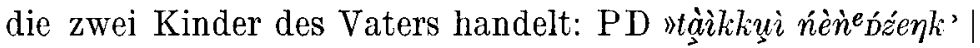

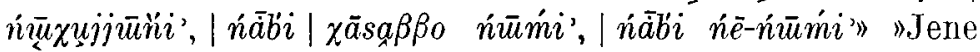
zwei Menschen | sind meine Kinder, | der eine ist mein Sohn, ! die andere ist meine Tochter» (64).

Das Prädikat drückt auch das im Satz nicht genannte Dualobjekt aus: (C) »tjiki meäkana | manj ouolämbangu-huju-n ( ouolämbangu-ie-n)" "In diesem Zelte | beginne ich sie [die zwei Knaben] zu speisen» (186; in der Variante des Prädikats 
weist - wie auch in anderen Fällen - das Pluralzeichen ${ }^{*} j[i]$ auf das dualische Objekt hin); njanaeuna auwalangahajude 'auf richtige Weise begann [der Vater] sie [die zwei

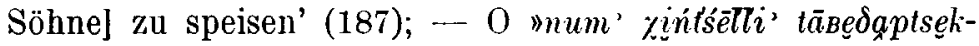

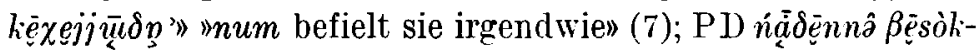

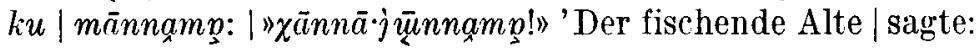
»Führe sie [die zwei Söhne] doch fort' $(339 ; \chi a n n \bar{a} \cdot j \vec{u}-<$ * yanna-yajū-).

Das Element $\chi a j i \bar{u}$ erscheint nicht nur im Prädikat, sondern auch im Namen des dualischen Objekts, ebenfalls

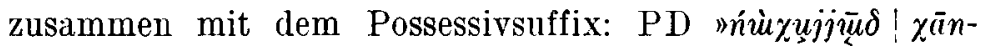

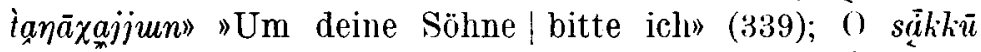

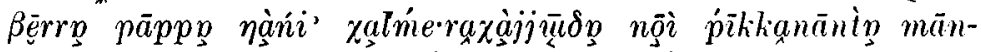

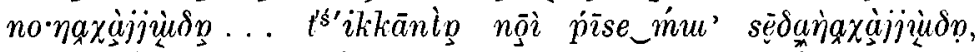

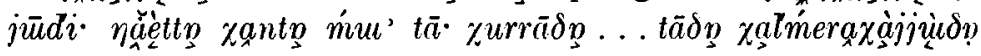

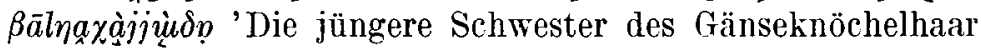
wieder wickelte ihre [zwei] Verstorbenen in die Schlittendecke aus Tuch... Darauf nähte sie sie in die tuchene Schlittendecke, in ihren zehnstrebigen Schlitten, dahin band sie (sie) ... Dann beförderte sie ihre Toten hinter sich' (461). - Das Element $\chi a j j \bar{u}$, das auf das dualische objekt hinweist, erscheint in einer Frage im verneinenden Verb: PD

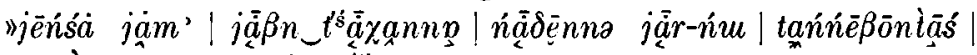

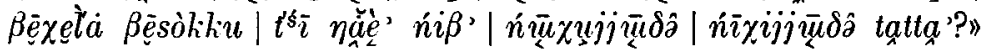
»Hinter dem Fluss, | dem Jenissei-Fluss, | der fischende Sohn von $j \vec{a} r \mid$ soll gewesen sein, | der Bēxela-Alte, | das ist er ja.|Seine zwei Söhne | ob er nicht gibt?» (338). Aus einer Erzählung zitiere ich einen Teil, wo mehrere Wörter vorkommen, die das Element $\chi a j u$ enthalten, die aber nicht in jedem Fall zur Bezeichnung des dualischen Objekts dienen: PD

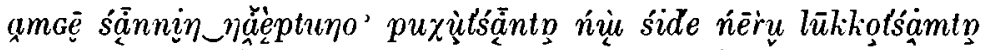

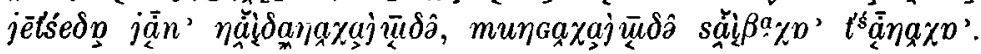

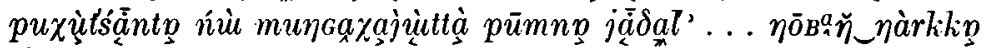

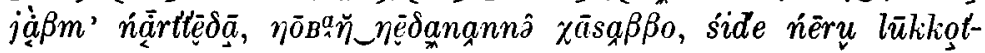

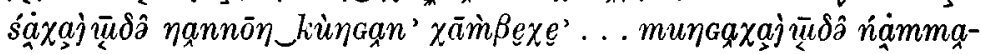

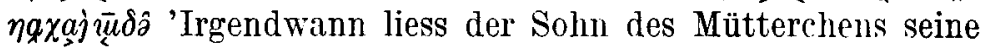
zwei Weidenpfeile in besitzloses Land gehen (d.h. schoss), seine Pfeile gingen ins Unabsehbare. Der Sohn des Mütter- 
chens begab sich auf die Wanderung hinter seinen Pfeilen her ... Er ging über einen grossen Fluss. Es ist ein mit 'Treibnetz fischender Mann, seine zwei Weidenpfeile waren in das Vorderteil des Bootes gefallen ... [Der Sohn des Mütterchens] nahm seine (zwei) Pfeile...'(120-121). Im ersten Satz drückt das Wort sid'e und der Singular des Wortes für 'Weidenpfeil' das Dualobjekt aus, im letzteren aber enthält das Objekt das Element $\chi a j \bar{u}$. Im zweiten und vorletzten Satz erscheint dieses Element im Subjekt des Satzes, im dritten Satz aber im Wort mit der Postposition, das auch ein Lativsuffix und ein Possessivsuffix trägt: muฑgaxajùtta $<$

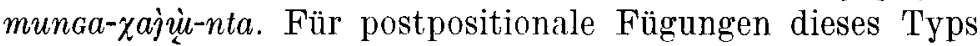

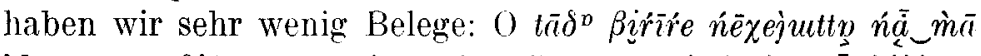

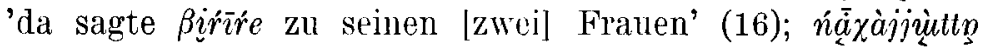

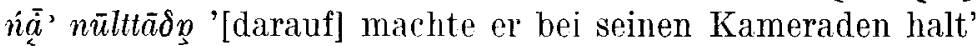
$(465)^{1}$

In einer Sage enthält das Subjekt, der Name eines paarigen

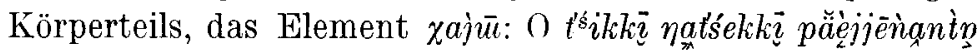

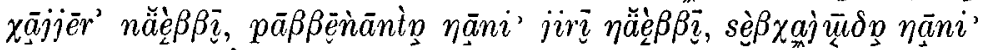
numgè $\chi \bar{e}$ ' $\eta \ddot{a} \dot{e} \hat{\beta} \bar{e} \chi \bar{e}$ ' 'Auf der Stirn dieses Kindes war die Sonne, in seinem Genick wieder war der Mond, seine [zwei] Augen wiederum waren [Du.] die [eig. zwei] Sterne.' $(15)^{2}$

Bei Castrén erscheinen das Element zaju und das Possessivsuffix im Namen des Rentiers als Subjekt des Satzes: tëjudeh $(\sim$ tehäjudE) siu malkumioih 'seine (zwei) Ren-

${ }^{1}$ Unklar ist das Element $\chi e^{\bar{e} m}(<\chi e n)$ in den beiden folgenden Sätzen:

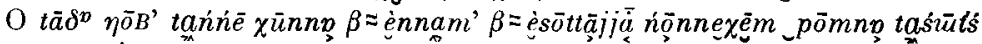
mimmōnty 'dann hörte man einmal Halbhund zwischen den Türpfosten seufzend gehen' (162; vgl. 171); 'T numrānno mantom' | jilšedp

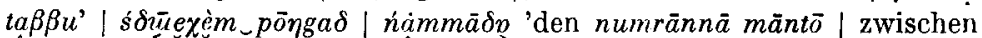
den Schulterblättern | nahm fest' $(376)$. Der Laut ${ }^{*} n$ im Element xèm kann zum Dualzeichen gehören, aber auch ein Lativsuffix sein.

${ }^{2}$ In einem Gesang aus dem $\mathrm{Nj}$-Dialekt fällt die ein Element $\chi_{3}^{a j j o ' o n}$ enthaltende Form des mit einer Postposition verbundenen Wortes auf:

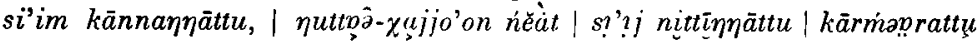
$n \dot{n} \bar{\imath}$ 'mich führten sie, | an meinen Händen | mich hängten sie | oberhalb ihres Toten' (416). In der Postposition néàa suffix des Ablativs. Ob der Kehlkopfverschluss im Flement xajio'on das Ablativsuffix bezeichnet? 
tiere / haben sieben mal ihr Geweih abgeworfen' (93). Bei Lehtisalo sehen wir die Form téxejiünì als eine Variante des Objekts side temi: O sarmik side tếm $i^{\prime} \chi \bar{a} \delta a \beta \beta i . ~ \chi \bar{a} \delta a \beta \beta \bar{\lambda}$

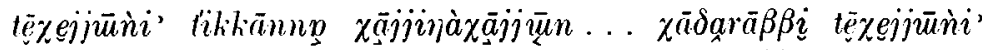

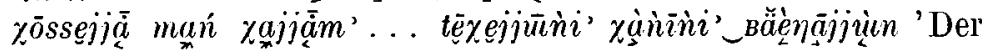
Wolf hatte zwei von meinen Rentieren getötet. Meine zwei getöteten Rentiere liess ich dort... Ich begab mich um neine zwei getöteten Rentiere zu holen... Ich legte die Rentiere in den Schlitten' (Mat 346-347).

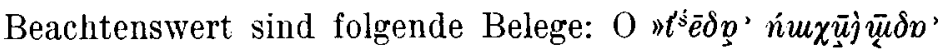
ńênù mallē $\chi \bar{o} \beta \beta \bar{e} \chi e^{\prime}$ " Nun haben eure Kinder schon eine Tochter [eig. Weib-Kind] bekommen» (8). Das Element $\chi u j j \bar{u}$ im Subjekt des Satzes und das Possessivsuffix der 2. P. Plur. drücken je ein mit dem Ehepartner lebendes Kind der beiden Ehepaare aus. Vgl. noch OD lëmmorōklōjjųong $j \bar{e} \delta^{\prime} \beta \vec{a} r{ }^{n} i$ ' yāmtrajaza' 'die kleinen Vögel [die beiden Vögel (les Riesenehepaare] setzten sich auf den Rand des Topfes'

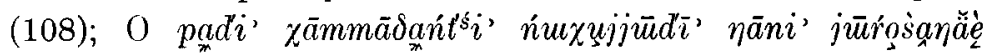

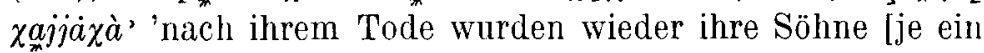
Sohn der beiden Freunde] Freunde' (31); 0 tāop jō $\bar{a} l l e ~ j \bar{e} r^{\prime}$

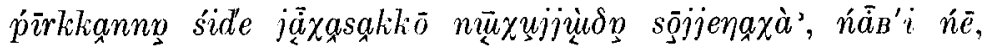

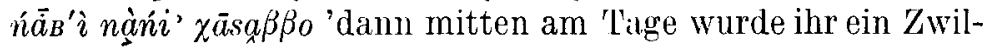
lingspaar geboren, das eine ist ein Mädchen, das andere wieder' ein Knabe' (456).

Nach sporadischen Belegen drückt das dualische Possessivsuffix am Namen des paarigen oder unpaarigen Körperteils aus, dass es sich um den Körperteil eines zusammenhängenden Paars (zweier Personen oder Rentiere) handelt: (C) tie pōngana $\mid$ side hattarie $|j \bar{a} d n g a h a|$ saeuvvatin|gajes 'unter den Rentieren | zwei grosse Rentiere | gehen, | ihre Augen geschlossen [eig. ging fort]' (252; zur volleren Form tin des dualischen Possessivsuffixes vgl. Gr. S. 255); - $0 t \bar{a} \delta^{0}$

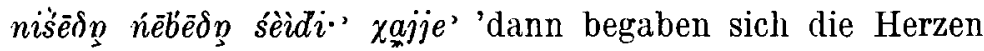
des Vaters und der Mutter fort (m.a.W. sie erschraken)'

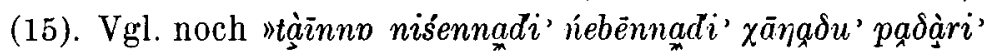
nénum 's $i$ " "dort eure Väter und eure Mütter rufen [Plur.] eure Tochter [eig. zwei Väter und zwei Mütter rufen die Tochter ihrer Kinder, eines Ehepaars]' (8). 
Ravila hat für die obugrischen (und samojedischen) Sprachen erklärt: "sehen wir uns Texte aus den obugrischen Sprachen an, so können wir keineswegs leugnen, dass obgleich da der Dual auch bei Substantiven begegnet, der Dualgebrauch trotzdem in hohem Grade ron ähnlicher Art wie im Lappischen ist. Der Dual kommt hauptsächlich beim Prädikat, bei den Pronomina und Possessivsuffixen vor" (a.a.O. S. 54, vgl. S. 55-57).

Das neuere Material beleuchtet mit vielen interessanten Einzelheiten den ausgedehnten und abwechslungsreichen Gebrauch des Duals im Juraksamojedischen, an der grundlegenden Feststellung Ravilas ändert es aher nichts.

Einige Fragen zur Bezeichnung der Pluralität

"Höchst schwankend sind im Jurakischen die Genitivund Accusativaffixe des Plurals, weshalb sie auch in der Tabelle nicht angegeben worden sind [vgl. §236]. Gewöhnlich können diese Casus durch den Nominativ Plur. ausgedrückt werden, zugleich kommen aber gewisse eigrentümliche Endungen für diese Casus vor . . . Hier wollen wir jedoch bemerken, dass der Genitiv immer die scharfe Aspiration (') annimmt, welche der Accusativ immer fortlässt, wenn dieser Casus nicht durch den Nominativ ausgedrückt wird" (Gr. $\$ 239$ ).

In den Punkten a-d des $\S 242$ fasste Castrén die Lautwandel zusammen, die in den Acc- und Gen.-Formen des Plurals zu beobachten sind, in $\$ \$ 244-246$ zeigte er im Rahmen der Deklinatiousparadigmen auch die Pluralformen. Zu beachten ist auch die folgende Feststellung: "In den nördlichen Dialekten kann ausserdem der Objectcasus des Plurals immer durch den Singular ausgedrückt werden, da sich die Zahl des Objects schon durch das Verbum bestimmen lässt. Ausserdem werden hier oft statt des Plurals gewisse collectivformen gebraucht” $(\$ 220){ }^{1}$

${ }^{1}$ Bo Wickman befasst sich mit der Frage des jurakischen Plur. Akkusativs in seinem Werk "The Form of the Object in the Uralic Lan- 
In Castréns und Lehtisalos Texten finden wir für den Gebrauch des Plurals kein so abwechslungsreiches Material wie für den des Duals. Wir müssen aber die Tatsache in Erwägung ziehen, dass die Ereignisse in den Texten im allgemeinen zwei Personen auftreten lassen, mehr als zwei Handelnde kommen ziemlich selten vor.

Die Bezeichnung der Pluralität durch Possessivsuffixe ist eine ebenso auffallende Eigentümlichkeit der juraksamojedischen Sprache wie der Gebrauch der Possessivsuffixe des Duals für die Bezeichnung der Dualität. Für die determinierende Funktion der Possessivsuffixe des Plurals, in erster Linie der 3. Person gibt es auch viele Belege: U jōrmańt'se

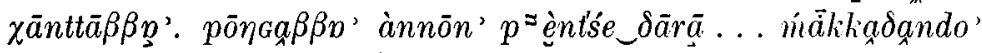

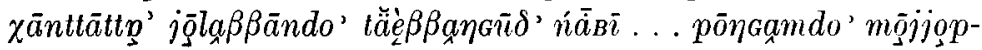
panaर̃ $\delta o^{\prime}$ ' 'Wir begeben uns das Zugnetz zu ziehen. Man muss das Zugnetz in das Boot legen ... Sie begeben sich ron ihrem Zelt und kommen zur Zugnetzfischereistelle... Die Anderen werfen das Schleppnetz aus' (Mat 370).

Beim Ausdruck der Pluralität kommt dem Prädikat die wichtigste Rolle zu. Das Possessivsuffix, das an das Prädikat tritt, bezeichnet das Subjekt (auch das im Satz nicht genannte Subjekt), die Pluralität des Objekts bezeichnet das Pluralzeichen ${ }^{*} j \varepsilon(i)$ vor dem Possessivsuffix: (C) siu baem leäkaptā-je-da 'sieben Steine spaltete er' (219); "hartta nise$n a d \mid h \bar{a} d a-i e-d a$ ( hadae-ie-da)» "deine eigene Väter| töte-

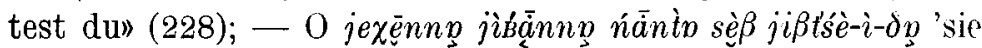
leimte mit Störleim die Augen ihrer Kameradin zu' (160); tāo jur' sềr dert weisse Renntiere | in die Krone der Lärche zog er' (205);

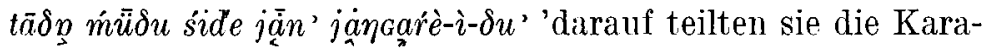
wanen in zwei Teile' (440).

guages» (Uppsala 1954) eingehend (S. 82-108). In der Rezension des Werkes Wickmans stellt A. J. Joki die Haupttypen des Plural-Akkusativs der zweisilbigen ${ }^{*} a-,{ }^{*} \ddot{a}$-, ${ }^{*} e$-Stämme und der einsilbigen Nomina vor (FUF XXXII Anz. 21-23). P. Hajdú behandelt in seiner Arbeit "The Form of the Object in Forest Yurak" (ALH X, 95-116) auch das Problem des Akkusativs auf $j$. Gizella Labádi entwickelt ihre Ansichten über den jurakischen Genitiv Plural (Nyelvészeti Dolgozatok 86. Szeged 1969). Sie beschäftigte sich auch mit der Herkunft des samojedischen Dualzeichens (NyK LXIX, 416-423). 
Das Pluralzeichen ${ }^{*} j \varepsilon(i)$ bezeichnet die Pluralität nicht nur im Prädikat, sondern auch im Namen des Nominativs Plur., des Objekts und im Nomen possessoris der possessiven Fügungen. Im Jurakischen existiert also ein Pluralstamm (plur. Grundform), der ein $*_{j \varepsilon(i)}$ Element enthält. Diese Grundform erscheint allein oder mit Possessivsuffix (auch mit dessen abgeschliffener Form) und mit dem das Possessivsuffix ersetzenden Kehlkopfverschluss versehen in der Funktion des Subjekts, des Objekts und des Nomen possessoris im Satz. ${ }^{1}$

Im folgenden habe ich einige Typen des Plurals der Nomina auf Grund von Belegen aus Castréns und Lehtisalos Texten untersucht.

Wir stellen uns die Frage, ob die Namen der paarigen Körperteile auch Pluralformen haben. Für den Dual des Wortes A u g e gibt es einen deutlichen Beleg (s. weiter oben, S. 224). In der Auflösung eines Rätsels aus dem PDDialekt sä̈é ' 'die Augen' (603) ist der Kehlkopfverschluss nicht als Ersatz des Dualzeichens, sondern des abgeschliffenen determinierenden Possessivsuffix der 3. Person aufzufassen; vgl. (Wb. 378) 'T sä̈è $\beta \delta p ~ \eta \bar{u} l_{i}$ ' ṕênnnā 'seine [des Verstorbenen] Augen wurden starr'; vgl. noch MB sē $\beta \check{p} \_p e \bar{e} n n a \beta \beta \bar{t}$ '

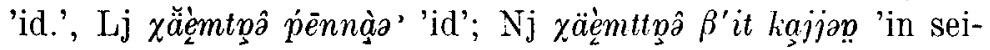

1 Der Ursprung des Pluralzeichens ist nicht geklärt. Seine Form fällt zusammen mit dem Suffix des aktivischen und passivischen Verbalnomens (und des Konjunktivs), ferner mit dem an die ursprünglichen $a$-stämmigen bzw. anderen Nomina tretenden Ableitungssuffix $* j \varepsilon(i)$. Ungeklärt ist auch das Verhältnis zum Adjektivsuffix $i$ (vgl. Ravila a.a.O. 43, Joki: FUF XXXII Anz. 40). Auch die Erklärung, die von mir stammt (vgl. ALH X, 89), ist abzulehnen. - Für den Gebrauch des PJuralzeichens $t$ gibt es keinen deutlichen Beleg. Das Element $d, \delta$, das ich vor Jahren für das Pluralzeichen in gewissen Prädikaten in der 3. Person hielt (vgl. ebd. 86), ist kein Ausdruck der Pluralität, sondern ein Rest des Possessivsuffixes (vgl. FUF XXXVIII, 156-225). - Lehtisalos Wörterbuch enthält zahlreiche Belege für die sacc. pl.-» bzw. "gen. pl.-" Form des entsprechenden Wortes. Diese sind meistens nicht im Rahmen eines Beispielsatzes angegeben. Da wir den Kontext nicht kennen, geben solche Angaben keinen Aufschluss über das Verhältnis von pluralischem Nom., Akk. und Nomen possessoris zueinander und über den Gebrauch dieser Formen. 
ne Augen kamen Tränen [eig. sein Augen-Wasser ging fort]' (ebd. 408).

In Castréns und Lehtisalos Wörterbuch (S. 408) lesen wir das Wort 'A u g e' als einsilbiges Wort. Aus Schlözers Wörterverzeichnis und aus den sporadischen Belegen der Texte kennen wir aber auch die zweisilbige Form: Schlöz. saiwa; (C) saeua-n jalamah 'meine Augen wurden klar' (299); saeuvvatin gajes 'ihre Augen geschlossen [eig. ging(en) fort]' (252);

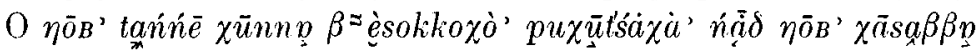

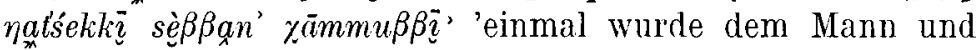
der Frau ein Knabe geboren („fiel in die Augen»)' (32; vgl. 15),

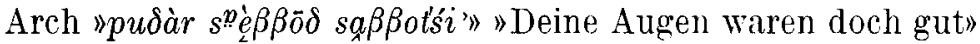
(180). Der Stamm $s^{p} \stackrel{e}{e} \beta \beta o$ - kann - wenn es sich nicht um Labialisierung handelt - auch ein Pluralstamm sein: $s^{p} e \beta \beta \overline{0}-$ $<s^{n} e \beta \beta a+-i$. Das Wort für 'Auge' kennen wir aus dem Tawgy als saime, aus dem Kamassischen als (C) sima, (D-J) sima, sima, sim̀. Das Element ma bzw. $\beta a$ fehlt im jen. sei, (D-J) $\vartheta e i$, ferner in allen selkupischen Angaben (Mat 81): N hai, K sai, B Jel Tas Kar sai, saj, MO sei, Tsch Tschl 00 sei. Als zweisilbiges Wort begegnet es in der Form NP saiji, in Lehtisalos Wörterverzeichnis sàjii (Mat 325), ferner im Wörterbuch von Prokofjev-Erdélyi: Tas saji (auch saj, haj). In den Formen (C) $s a i-j i$, (L) $s a j-j i$ kann das Element $j i$ das Pluralzeichen sein. - In den finnisch-ugrischen Entsprechungen des Wortes erscheint ein Element ${ }^{*} m \ddot{a} \sim m$. Bei der Etymologie des Wortes geht Paasonen (Beitr. 17, 212) von einer Konsonantenverbindung uralisch (fgr.) *-lm- aus, Collinder (Comp. Gr. $\S 259$ Note) von einer inlautenden Verbindung *-lm- $\sim$ *-lm-. Man könnte aber auch die Möglichkeit erwägen, dass das fgr.-samojedische ${ }^{*} m \ddot{a} \sim m$ bzw. das jurakische $* \beta \ddot{a} \sim \beta$ (mit passivem Sinn) nicht zum Stamm gehört, sondern ein Ableitungssuffix ist, und dass das Element $j, i$ des einsilbigen Stammes in den samojedischen Belegen eine Fortsetzung des ursprünglichen inlautenden $* l$ ist. Was das Verbalnomensuffix ${ }^{*} m \ddot{a} \sim m$ betrifft, finden wir darüber Aufschluss bei Lehtisalo Abl. Suff. S. 91-92, 93, 108. Eine Bedeutung des uralischen Verbalnomens auf ${ }^{*} m$. ist: „das Mittel oder der Ausführer der Handlung». Das Wort 
für 'Auge' ist also ein Verbalnomen in den uralischen Sprachen, seine Bedeutung ist: 'das, was sieht, womit man sehen kann'. In der ersten Silbe des uralischen Verbalstammes dürfte $i$ oder $e$ gestanden haben. (Jurakisch $s \bar{e}-<s \check{a ̈ e} \bar{e}$, săl- <*saje-). Vgl. Witsen saje-w 'de Oogen'.

Fuss, B e in. In Castréns Texten ist das Wort bzw. der Stamm in mehreren Varianten zu finden: $\eta a e^{-} \sim \ddot{a} e^{-}(42$, $44,45,60,75,140$ usw.) $\sim \bar{a}(75,302)$. Im Wörterverzeichnis von Schlözer erscheint der zweisilbige Stamm: naje- $\beta$ ['mein Fuss']. Der zweisilbige Stamm findet sich auch bei Castrén:

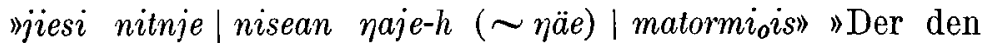
Eisengürtel trägt [Männername], | meines Vaters Füsse | schnitt er ab" (92). Da in Castréns Texten in zahlreichen deutlichen Belegen das auslautende $h$ das Zeichen des stimmlosen $i, i$ (vgl. waldjur. $ə$ ) ist, kann angenommen werden, dass die Form $\eta a j e-h\left(<^{*} \eta a j e-i\right)$ eine pluralische Grundform ist. (Im Text handelt es sich um das Abschneiden beider Füsse.) Auf Grund der Belege Schlözers und Castréns kann es für wahrscheinlich gehalten werden, dass der zweisilbige Stamm najedurch Abschleifung des Endvokals einsilbig geworden ist: der ursprüngliche inlautende Vokal verwandelte sich mit dem erstsilbigen velaren Vokal zu einem Diphthong; die Palatalisation des ursprünglichen velaren Vokals ist eben unter dem Einfluss des $i$-Elements des Diphthongs erfolgt.

In Lehtisalos Texten können wir Stämme vom Typ näàe-, $\eta \check{a ̆ i}$ - nachweisen. In diesen fällt die Länge (Halblänge) des zweiten Elements des Diphthongs auf. In einem aus dem waldjurakischen $\mathrm{Nj}$-Dialekt aufgezeichneten Gesang erscheint

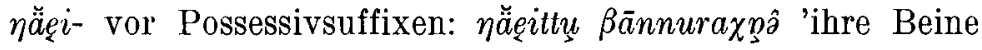

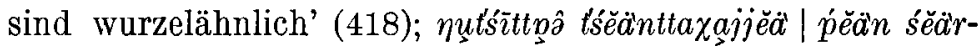

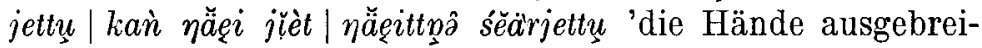
tet | banden sie ihn an ein Holz, | gegen die Strebe des Schlittens | banden sie seine Füsse' (413). Die Form nutśí- 'Hände' ist ein deutlicher Pluralstamm, das Prädikat enthält auch das auf das pluralische Objekt hinweisende Element $j e$; so können wir als sehr wahrscheinlich annehmen, dass das $i$-Element im Stamm $\eta \ddot{a} e^{-i-}$ das Zeichen der Pluralität ist. Die Längung des zweiten Elements des Diphthongs in den Stäm- 


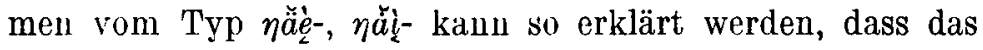
die Pluralität bezeichnende Element $i$ mit dem zweiten, ursprünglich kurzen Vokal des Diphthongs verschmolzen ist. ${ }^{1}$ Auf Grund der bei Lehtisalo vorhandenen Stämme $\eta \ddot{a ̈ e ̀-} \sim$ $\eta \ddot{a} e ̨ i$ - kann gefolgert werden, dass der Pluralstamm den Sin-

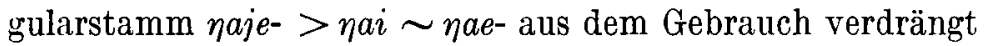

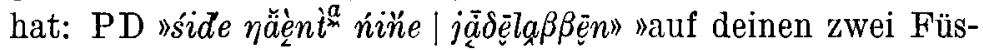

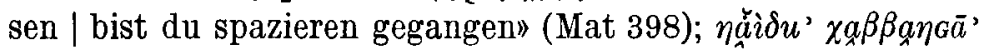
'die Beine fielen um' (340).

$\mathrm{H}$ a $\mathrm{n}$ d. Die Singularform ist ein Wort mit $a$-Stamm in den Tundra-Dialekten des Jurakischen und in einigen waldjurakischen Mundarten: (C) $\eta u d a,(\mathrm{~Wb} 44)$ OBS $\eta u \delta p, \eta \grave{u} \delta \grave{a}$;

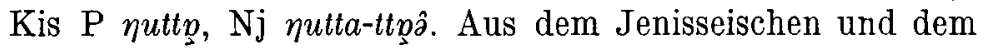
Kamassischen kennen wir es ebenfalls als a-Stamm, wie auch aus dem Tas-Dialekt des Selkupischen (Prok.-Erd.): uta-mi 'meine Hand', utamti musiltat 'wasche dir die Hände'.

In Castréns Tundrajurakischen Texten finden sich neben Sg.-Nominativen wie $u d a, u \delta a$ bzw. neben den Stämmen $u d a-$ auch die Nominativformen $u d e \sim u \delta e \sim u \delta e h:$ mienaseända ō $\delta$ njanaej nienets | äevuih, | taritsiongäe | hämuvioih, | $u \delta e(\sim u \delta e h)$ njamvaeda, | peängad ( piengadie $\sim$ piegdie $)$ juhih | taritsion pumnah." "Wirklich | ein Samojede war es, | als Haar fiel er, | die Hand fing ihn auf, | von der flachen Hand verschwand er, / die Hand verschwand / nach dem Haar» (160). Der Stamm udeh ist genau eine solche pluralische Grundform wie najeh 'Füsse'. Aus dem Stamm * $u d a+i$ entstanden die Formen ${ }^{*} u \delta a i>u \delta e i>u \delta e^{1}$ Die Stämme $u \delta e \sim u t e$ sind also Pluralstämme, die - wie auch aus Castréns waldjurakischen Paradigmen zu sehen ist, - in einige mit Kasussuffixen versehene Singularformen eingedrungen sind (vgl. Mat 306). In den Pluralstämmen (C) $u d i-\sim(\mathrm{L})$

\footnotetext{
1 Die Länge bzw. halbe Länge des zweiten Elements der Diphthonge vom Typ ẳè lässt sich nicht in allen Fällen mit der Verschmelzung des Pluralzeichens erklären.

Durch eine anders gerichtete Entwicklung hat sich aus dem Stamm * $u \delta a i$ der Stamm $u \delta \bar{a}$ - entwickelt: MS "sidemíói $u \delta \bar{a}-\beta \chi \bar{a} j \bar{j} i$ 'meine zwei

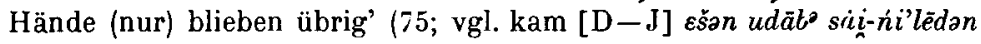
'die Hände der Kinder reissen sie $a b$ ' [91]).
} 
$u d i$ - hat sich das Pluralzeichen ${ }^{*} j(i)$ nicht unit dem zweisilbigen, vokalisch auslautenden Stamm verbunden, sondern ist an den einsilbigen konsonantischen Stamm getreten: (C) $u t-j i$ (Mat 307) $\sim(\mathrm{L}) \eta u d^{i} i-, u d i$.

Die pluralische Grundform wird selten ohne Possessivsuffix gebraucht: (C) side atsekih haruana jienadi'eh $\mid u \delta i$ njamg $\bar{a}$ 'Zwei Knaben | ihre wollende Bogensehne | mit der Hand erfassten [eig. die zwei Hände der zwei Knaben erfassten (Du.) ihre wollende Bogensehne (Du.)]' (268); "pi jiernje | harna njāna udih | muejouna | njämbiua ( njambina) jālombioehanda ( jalombioihanda)" "Um Mitternacht | die Hände [je zwei] von einander | fest | hielten wir | bis zu Tagesanbruch» (164).

Die pluralische Grundform erscheint als das Subjekt des Satzes mit Possessivsuffixen: (C) mudin bieres | nim aevvadāngu" "Solange meine Hand aushält, | höre ich nicht auf»

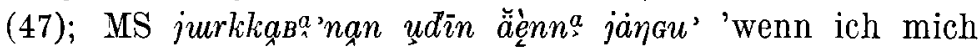
erhebe, habe ich weder Hände noch Füsse [eig. meine Hände - meine Füsse sind nicht vorhanden]' (593; das Possessivsuffix der 1 . P. Pl. wird mit dem Stamm udi- in abgeschliffener Form, mit dem Wort ä̈é- 'Füsse' in seiner volleren Form verbunden); T $\eta u d^{\prime} i \delta j \bar{a} \eta \bar{u} m m p^{\hat{\jmath}}$ ' 'deine Hände wurden russig'

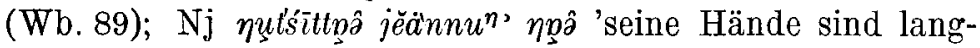
sam' (ebd. 98). - Das an den Pluralstamm tretende Possessivsuffix bezeichnet je zwei Hände (Füsse) bzw. je eine Hand (einen Fuss) zweier bzw. mehrerer Personen: "amae nid $i$,

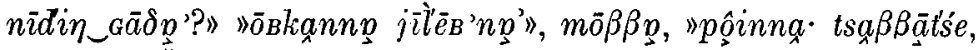

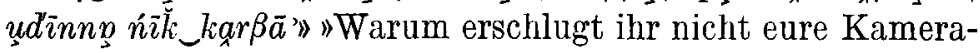
den?" "Als wir zusammen lebten", sagte er, "sind unsere Beziehungen gut gewesen, unsere Hände [je zwei] wollen nicht»

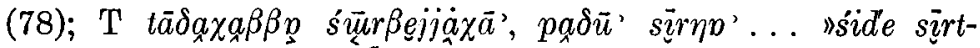

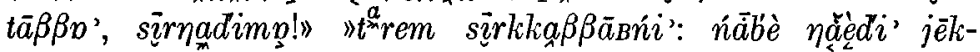

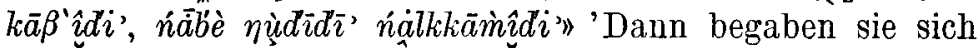
um zu laufen. Sie schauen ... »Unsere zwei Schauer, schauet doch!» So blicken wir: ihr eines Bein haben sie (aus der Bindung) gelöst, ihre eine Hand haben sie (hinter dem Gür-

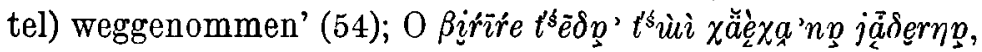

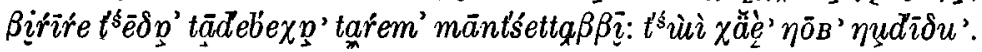




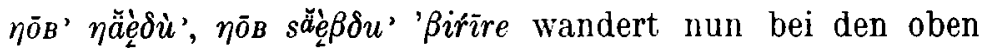
befindlichen Gewittergeistern. $\beta$. hat jetzt zu den Schamanen also gesagt: die oben befindlichen Gewittergeister haben eine Hand, ein Bein, ein Auge' (17). In den folgenden Worten des "Erdalten-Grossvaters" drückt der Pluralstamm + Possessivsuffix der 1. P. Du. zwei Hände einer Person aus: mańn

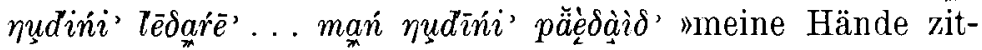
tern ... meine Hände ermüdeten" (3). Die Prädikate sind Pluralformen.

Der Pluralstamm ist, meistens mit dem Possessivsuffix der 3. P. versehen, das Objekt des Satzes: (C) panīda $\eta a_{-}$ dam'ah, | udidan seärornam'ah 'ihre Kleider riss ich herunter, | ihre Hände band ich' (288); sidem mungum äedäda: $\mid$ njāvih mungota | udida matorngah 'zwei Pfeile | liess sie (auf einmal) los: | der eine Pfeil von ihr | durchschnitt seine Hände' (263);

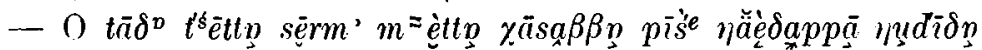
$m a \bar{l} l^{\prime}$ śáttòlaptàion 'dann liess der vier weisse Zugtiere haltende Mann, indem er die Mäuse ausschirrte, von diesen seine Hand ganz (zer)beissen' (159); vgl. noch Sjo (Kan) yุdī ăèdəo māl ṕénnarāido' 'sie streckten ihre Arme, ihre Beine alle auseinander' (Wb 378). - Im Namen des pluralischen Objekts ersetzt der Kehlkopfverschluss das abgeschliffene Pos-

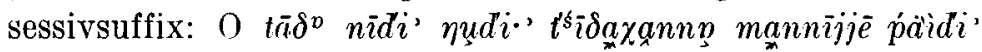
'sie [Du.] fingen dann an, einander im Schatten der Hände [je zwei Hände] zu betrachten' (32). - In der Funktion eines Nomen possessoris erscheint der Pluralstamm mit Possessivsuffixen versehen. Eine solche als Possessivverhältnis zu bezeichnende Fügung entspricht dem finnischen Ausdruck vom Typ is ä n i t a 10 : (C) hānda punjäd |tīnsienda njalka'à, | sanoāda, | peangatata wātam | udita haran |moiāda 'Aus dem hinteren Teile seines Schlittens/zog er sein Lasso heraus, | wickelte es auf, | was nicht in seiner Hand | Platz hatte, | wirft er um den Ellbogen' (34, vgl. 49, 55). Der mit dem Possessivsuffix der 3. P. Sg. versehene Pluralstamm wird in singularischem Sinn gebraucht: es kann nur von der Biegung des einen Armes die Rede sein, die andere Hand wickelt das Lasso auf. - Bei Castrén erscheint die pluralische Grundform im Ausdruck 'Finger' [eig. die Verzweiğıng der Hände] 
für sich in der Funktion des Nomen possessoris: hartta njäto | $(\sim$ njātoh) udi tārk | njamāje ( njamāja) 'die Finger | ihrer eigenen Kameraden |mögen sie festhalten' (163), vgl. OD

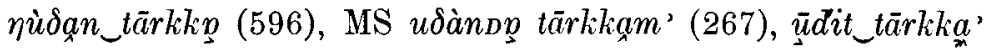
'die Finger (vor dem Daumen)' (595). — Das Wort mit der Postposition, der mit dem Possessivsuffix der 1. P. Du. versehene Pluralstamm, kommt im folgenden Satz in der Be-

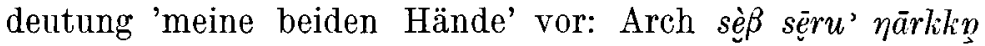

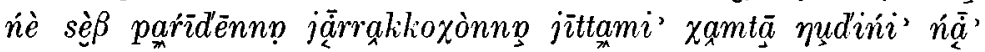
'Schwarzauge, die Frau des ältesten Hellauge, schüttete mir mit der Kelle Wasser auf meine [beiden] Hände' (437).

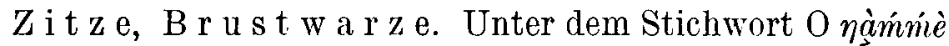
findet sich auch die "acc. pl».-Form des Wortes aus demselben

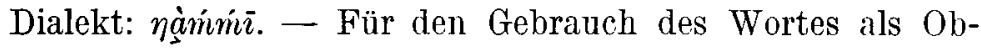
jekt begegnen sporadische Belege auch in den Texten; in diesen ist die pluralische Grundform mit Possessivsuffixen

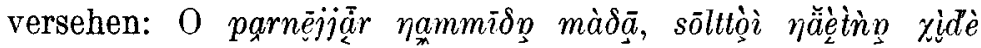

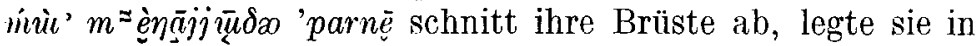
einen goldenen Napf mit Fuss' (104). Das Prädikat des zweiten Satzes weist auf ein dualisches Objekt hin. Auf derselben Seite weist in einem interessanten Beleg auf das dualische Objekt im ersten Satz das Pluralzeichen $j \bar{e}\left(<{ }^{*} j \varepsilon+\right.$ $j \varepsilon[i])$, im zweiten das Element ${ }^{*} \chi a j j \bar{u}$ hin: $t \bar{a} \delta^{p}$ tikk $\bar{a} \delta \beta \approx \grave{e} j-$

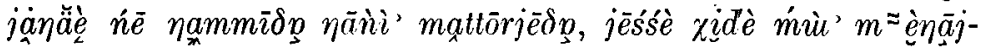
$j \bar{u} \delta \infty$ 'dann schnitt das Einbein-Weib wieder seine Brüste $a b$, tat sie in einen eisernen Napf' (ebd.). In der dritten Angabe erscheint das Element $j \bar{e}$ in beiden Sätzen: $\dot{m}^{\prime} \bar{t} t_{a}^{\dot{a}} t^{\prime} \bar{u}-$

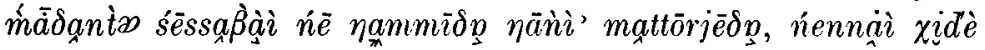
$\dot{m} u^{\prime} p^{z}$ ènjē $\delta p$ 'nachdem er in das Zelt hineingegangen war, schnitt wieder das Harzriesenweib seine Brüste ab, tat sie in einen silbernen Napf' (105).

Die Namen der pa a rig e n G e g e n st ä n d e lieferı beachtenswerte Aufschlüsse. In den Texten finden wir mehrere Belege für das Wort $\mathrm{St}$ i e f e l. Die pluralische Grundform erscheint in mehreren Belegen als Objekt des Satzes: 0 tāon

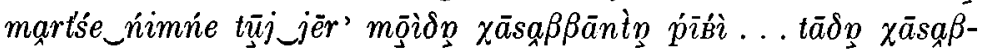

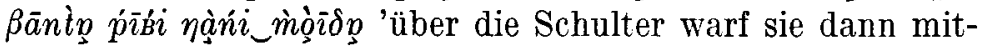
ten in das Feuer die Stiefel ihres Mannes... dann warf sie 
wieder die Stiefel ihres Mannes' (459); PD $t^{\xi} i k k a \bar{n} t p$ ràní

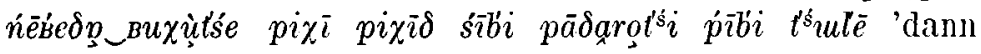
brachte wieder seine Mutter, die Alte, von draussen die siebengemusterten Stiefel herein' (Mat 403). - Häufiger kommt in dieser Funktion der Pluralstamm mit Possessivsuffix vor:

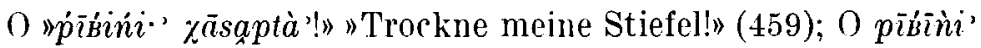
jănkām' 'ich klopfte den Schnee von meinen Stiefeln' (Mat

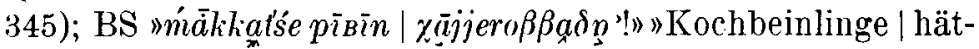
tet ihr geben müssen!» (214). In einigen Daten ist das Possessivsuffix der $3 . \mathrm{P} . \mathrm{Sg}$. mit dem Pluralstamm verbunden:

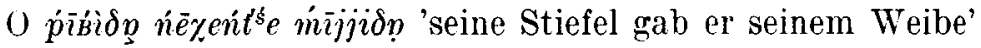

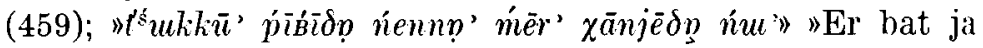

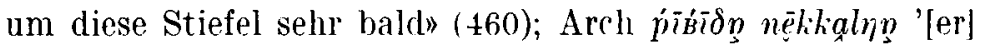
ergriff seine Stiefel' (173).

Für den Singular des Wortes $S \mathrm{k} i, \quad \mathrm{~S}$ c h n e e s c h u h haben wir nur sporadische Belege, vgl. (Wb 216) O OP lampp, P sampo. In einigen Ausdrïcken, in Beispielsätzen erscheint auch die singularform: OP lampa jinñe 'Riemen, mit dem der Fuss am Ski festgebunden ist', P $\eta \bar{o} p$ sampam kō $\eta \bar{a} t$ 'ich fand einen Ski'. Es ist klar, dass es sich bei diesen Beispielen nicht um ein Exemplar, sondern um ein Paar Skier han-

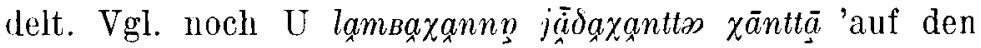
Skiern geht er' (Mat 364). Die Form Sjo lamsāa (Wb) können wir als einen Pluralstamm betrachiten: <*lamba $+i$; mit

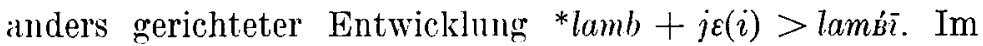
letzteren Fall wurde das Ableitungssuffix $* j \varepsilon(i)$ mit dem konsonantischen Stamm verknüpft. -- Die mit einem Possessivsuffix versehene pluralische Grundform ist das Objekt des Satzes: (C) lambin sieram'ah 'meine Skier' band ich an meine Füsse' (274); MB lambīn nèoklialnam' zạ̀ maxaañádo '[ich] zog meine Skier von der rechten Seite des Schlittens hervor'

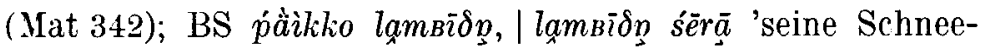
schuhe ohne Fell, | seine Schneeschuhe band er (an seine

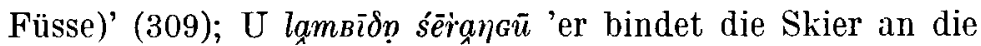
Füsse' (Mat 364). Im folgenden Beleg kommt dieselbe Form in zwei Funktionen vor, dreimal als Objekt, einmal - mit dem das Possessivsuffix ersetzenden Kehlkopfverschluss

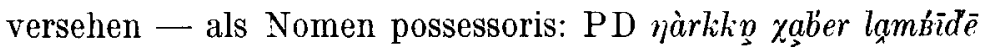




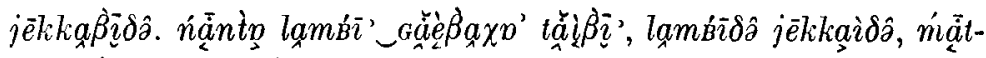

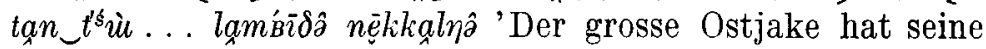
Schneeschuhe losgebunden. Er traf neben den Schneeschuhen seines Kameraden ein, band seine Schneeschuhe los, trat in das Zelt . . zog seine Skier an' (119).

Pluralformen vom Typ (C) »jaha 'Fluss': Gen. Plur. jasi."

In Castréns hinterlassenen Manuskripten hat Paasonen eine skizzenhafte Grammatik in lateinischer Sprache gefunden, aus der er folgende Zeilen zitierte (Beitr. 179): "Saepe mutatur in lingua Samojedica littera $h$ ante $i$ in $s$, exp. gr. mahà, tergum, jaha, flumen, gen. plur. masi, jasi. Mutata vero post $n$ littera $h$ in $g$, mutatur necesse est $g$ in $z$, ex. gr. jienga, passus, seänga, campanula, gen. plur. jienzi, seänzi. Ita quoque $k$ ante $i$ in $c$ transit, ex. gr. tubka, securis, nierka, salix, gen. plur. tubci, nierci.»

Fluss. Paasonen studierte auch Castréns damals noch nicht herausgegebene waldjurakische Aufzeichnungen und stellte fest: "Im Knd. [Kondinschen] Dialekt liegt... ein Wechsel $h \sim \check{s}, k \sim \xi$ vor.» (ebd.) In den "Materialien» lesen wir das Deklinationsparadigma des Wortes 'Fluss' von uralischer Herkunft (S. 299). Singularformen: Nom. jaha; Gen. jaha mal 'der obere Lauf des Flusses', jahangaeu 'Flussufer'; Akk. jaha od jaham, Dat. jahan gaja 'er ging zum Fluss' usw. Pluralformen: Nom. jaha jaśi, jeśä; Gen. jahah jessi $(-i)$; Akk. jeśi. Vgl. Prosekutiv jeśimana, jeśemana. Unter den Pluralformen fallen die zweierlei Formen des Nominativs und Genitivs auf. Der Gen. Plur. fällt mit dem Nom. Sing. und Plur. zusammen. Die Form jas̉i (jeşä) des Nom. Plur. ist aber im wesentlichen identisch mit der Form jeśi des Akk. und Gen. Plur. Da bei Castrén das auslautende $h$ in zahlreichen deutlichen Fällen - wie schon weiter oben erwähnt - ein Zeichen des stimmlosen $i, i$ (L. waldjur. o) ist, kann in der Endung $h$ des pluralischen Nomen possessoris jahah das Zeichen der Pluralität erkannt werden: jahah $<{ }^{*}$ jahai $>{ }^{*} j a h a+j \varepsilon(i)$. Die pluralische Grundform jahah ist mit den pluralischen Grundformen (C) najeh 'Füsse', udeh 'Hände' in der Form identisch. Bei allen diesen Formen tritt das Pluralzeichen an den zweisilbigen, vokalisch auslauten- 
den Stamm. Nimmt aber der einsilbige, konsonantische Stamm das Pluralzeichen an, so palatalisiert das Element ${ }^{*} j \varepsilon(i)$ den ursprünglichen inlautenden $*_{k}$-Laut und der Lautwandel - ${ }^{*} k->-s^{-}\left(-s^{\prime} s^{-}\right)$tritt ein: ${ }^{*} j a k+j \varepsilon(i)>>{ }^{*} j a k e(i)$ $>j a s s i \sim j e s s i$. Bei Lehtisalo sind (Wb. 79) "gen. pl.» Nj. jaśśi und »acc. pl.» O jeśsi völlig identische pluralische Grundformen. ${ }^{1}$ In einem Beispielsatz fällt der das Possessivsuffix der 3. P. Sg. ersetzende Kehlkopfverschluss am Ende eines pluriłlischen Nomen possessoris auf: Sjo (Kan) jeśsi' sęoro óktip 'in den Flüssen ist viel Eis'. In den Texten habe ich für den Gebrauch der Formen jaśi jeśśi keinen Beleg gefunden.

$\mathrm{R}$ ü $\mathrm{c} \mathrm{k}$ e n. In Castréns waldjurakischen Aufzeichnungen (Mat 301) ist der "Gen. Plur." des Wortes maha 'Rücken' maśi $\sim$ mase. In Lehtisalos Texten erscheint nach vereinzelten Belegen die pluralische Grundform mit dem Possessivsuffix bzw. mit dem dieses ersetzenden Kehlkopfverschluss:

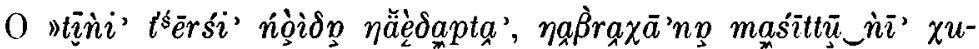

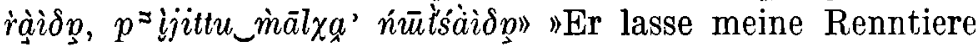
nicht leer gehen, er binde auf ihren Rücken Essen, er mag

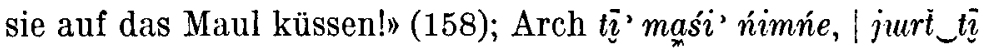
ńimń | $m$ ¿ènílaptāon 'über die Rücken der Renntiere, | über hundert Renntiere, | warf er schlau (das Lasso)' (174).

P o l a r f u c h s. Wir kennen seine "Gen. Plur.»-Form noši, nośi des Wortes noho aus Castréns Grammatik (\$ 242) und seinen waldjurakischen Aufzeichnungen (Mat 301). In Lehtisalos Wörterbuch (S. 290) erscheint in einem der Beispielsätze die mit dem Possessivsuffix der 3. P. Sg. versehene Form nōś-

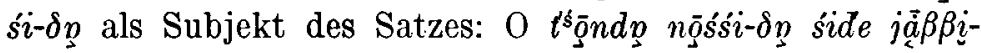
mannp lẳnkapti.' 'seine Füchse und Polarfüchse hängen an beiden Brustseiten'. In einem Ausdruck (ebd.) tritt die Grundform in der Funktion eines Nomen possessoris auf: O nōš̀ tal $\beta p$ jìr 'Monat des Polarfuchsfangs (Oktober)'; das Verbalnomen tal $\beta p$ bezieht sich wohl auf die Jagd mit der Falle, vgl. Wb. 461: O tallāa 'schliessen, zumachen'. Auch aus dem P-Dialekt des Waldjurakischen haben wir einen Beleg, ein

\footnotetext{
${ }^{1}$ Nach einem anlautenden $j$ - findet man für die Entwicklung eines erstsilbigen velaren Vokals (vgl. fi. joke-) zu einem palatalen Vokal mehrere Beispiele im Jurakischen.
} 
Nomen possessoris mit Kehlkopfverschluss am Ende: nōśı

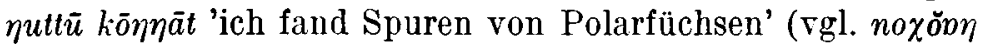
$\eta u \grave{t}$ kō $\eta \bar{a} t$ 'ich fand die Polarfuchsspuren', ebd.). Aus den Texten kann ich nur ein einziges Beispiel zitieren, in diesem ist die mit dem Possessivsuffix der 3. P. Du. versehene pluralische Grundform das Objekt des Satzes: O tāop $t^{\prime s} i k k i$

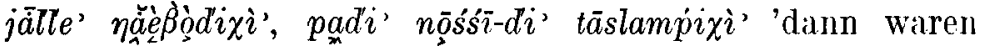
sie [Du.] den Tag am Platze, sie wählen Eisfüchse' (443). Das Pluralzeichen ${ }^{*} j \varepsilon(i)$ ist auch in diesem Beleg an den konsonantischen Stamm getreten: ${ }^{*}$ nok $+j \varepsilon(i)>>{ }^{*}$ noki $\sim$ nośsi $\sim$ nos̉i.

A x t, B e i l. In Castréns Wörterbuch heisst der Nom. Sy. tubka, in seinen waldjurakischen Aufzeichnungen (Mat 297) tubke, tupke. Im letzteren Wort mag sich der $\varepsilon$-Laut in der zweiten Silbe aus einem Diphthong entwickelt haben (vgl. Wb 498): waldjur. tupkp̧à. Auch der à-Laut der Form U tuskà lässt sich wohl auf einen Diphthong zurückführen. Für die pluralische Grundform kann ich aus Castréns Texten einen, aus Lehtisalos Texten ebenfalls einen Beleg anführen: (C) sale mälhana | opoj waetuh | jiesie äevuih | mung tiebiroma | tubtsi-tammaraha 'am Ende der Hügelhalbinsel | war ein fortgesetztes Zelt, | ein eisernes, | von Pfeilen getroffen ! ist es wie von der Axt geschlagen' (13); vgl. c. tubtji-tammaraha

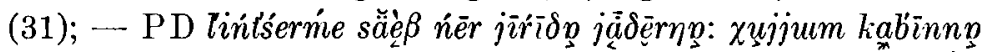

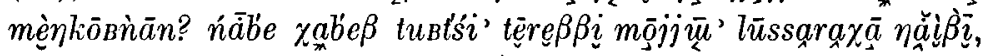

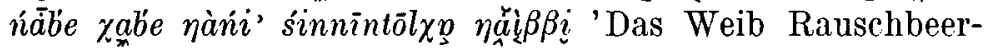
auge denkt: welchem Ostjaken werde ich sein (gehören)? Der eine Ostjake war den Knollen mit den Äxten abgeschlagener Äste ähnlich, der andere Ostjake wieder war mir ähnlich' (168). Im Wörterbuch (S. 117) findet sich der folgende

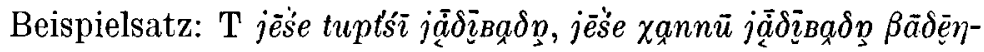

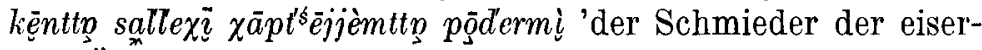
nen $\ddot{x} x t e$, der Schmieder der eisernen Schlitten, der Geist der Landzungenanhöhe Wadenky schirrte sein Öchslein an.' ${ }^{1}$

1 Paasonen hat sich auch mit dem weiter oben behandelten Lautwandel im Kapitel: "Exkurs. Übergang eines palatalen Verschlusslautes in einen $\dot{c}$-Laut im Samojedischen" (Beitr. 178-198) beschäftigt. Nach ihm ist vor $i(e)$ ein Lautwandel $k>c$ erfolgt, und die Laute $s, s(z)$ können aus dem $\dot{c}$-Laut abgeleitet werden. 
F u c h s. (C) "tôna: "Gen. Plur." tôn' od. ton " (Gr. S. 122). In Lehtisalos Wörterbuch (S. 518) heisst der "acc. pl.» in den waldjurakischen $\mathrm{Nj-}$ und P-Dialekten tśöö. - In Castréns Texten bedeuten die Formen tion $\sim$ dion $\sim$ djon - der deutschen Übersetzung zufolge - pluralische Objekte: salen kārdāna | pīndana hāsauah | paridieni djon | mirasi paerna äkka jieruo illah 'in Obdorsk | der Mann, der Werkbäume suchte | schwarze Füchse | schenkt den grossen Richtern'

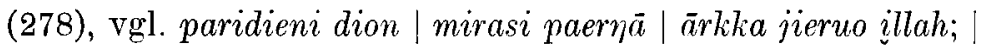
jieru mōjuku'ah | tjōn muojuku'ah 'schwarze Füchse schenkt [er] | den grossen Richtern; | die Richter werfen | Füchse werfen sie' (279; auf derselben Seite lesen wir auch die Variante tiōn); vgl. noch tjēta tidikou | hōrakätji dion | tion miritie'eh 'meine vier Mutterbrüder | schwarzbrüstige Füchse, | Füchse schenken sie' (282). - Nach der Übersetzung tritt der zweisilbige Stamm in genau solcher Funktion auf: paridieni djōna | tjōn(a) mirti'eh | uli yōkauna 'schwarze Füchse | Füchse er schenkte | sehr viel' (280). In diesem Satz ist das Wort 'Fuchs' ohne Zweifel eine Nom. Sg.-Form, cin unbezeichnetes Objekt, und die pluralische Bedeutung wird im Wort $\eta \bar{o} k a$ 'viel' angegeben. Es ist sicher, dass anch die einsilbigen Formen tion $\sim$ dion usw. keine Pluralformen sind, sondern Formen des Nom. Sing. djona $\sim \operatorname{iōn}(a)$ mit abgeschliffenem Ende. Die Tiernamen werden in den finnischugrischen und den altaischen Sprachen als Namen von Sammelbegriffen bekanntlich im allgemeinen im Singular gebraucht. Das Wort $\eta \bar{o} k a$ 'viel' drückt die Pluralität auch im folgenden Satz aus: noho $(\sim$ nohö), tjuonjä $(\sim$ tjōnjeh $), \mid$ tōs sabie nōka 'Polarfüchse, Füchse, Zobel sind sehr viel' (177). In diesem Satz ist die Variante tjōnjeh wohl eine Pluralform, vgl. die weiter oben erwähnten Formen najeh 'Füsse', uðeh 'Hände', jahah 'Flüsse'.

In den aus Castréns Texten zitierten Formen des Wortes 'Fuchs' fällt das inlautende - $n$ - auf. In Castréns Wörterbuch lesen wir aber die Form tóna, in Lehtisalos Wörterbuch (S. 518) in den Tundra-Dialekten tōnnne (O t'sōnné). Aus dem $\mathrm{U}$-Ts-Dialekt ist tónńnè; aus den BS- und Kan.-Dialekten, wie aus dem Waldjurakischen, sind die Formen auf Diphthonge

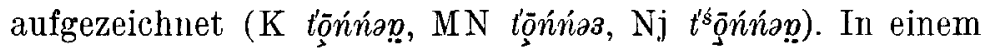


Zaubergesang lesen wir aber eine Form, die sich mit der Nom.-Sing.-Form tjōna djōna bei Castrén identifizieren

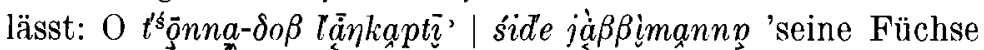
hängen | an beiden Schlüsselbeinen' (537). In Castréns waldjurakischen Aufzeichnungen (Mat 302) ist das Wort tjoon-jä 'Fuchs' eine mit *je gebildete Ableitung. Der Stamm tjoon-ist mit den singularischen Grundformen tion, dion $\sim$ tjon, djon aus Castréns Texten identisch, die aber den Endvokal abgeworfen haben. Der Stamm tjoon ist auch in der Singularform der possessiven Deklination vorhanden (Mat 309). 1. tjoon-ja-u 'mein Fuchs', 2. -ja-r, 3. -jä-da. Wir finden ihn auch bei Lehtisalo (Wb 290) $t^{\prime s} \bar{o} n-\delta p$ 'seine Füchse', richtiger 'sein Fuchs'. Die Form tjōnjä kommt auch in Castréns

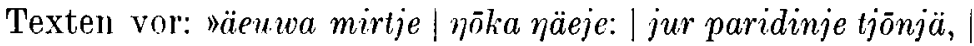

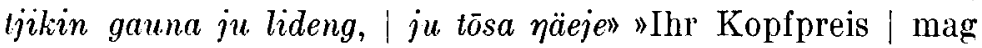
gross sein: | hundert schwarze Füchse, ausserdem zehn Biber, | zehn Zobel mögen es sein” (292). Die Subjekte des Satzes sind alle Nom.-Sing.-Formen; ihre pluralische Bedeutung wird mit Numeralen und dem Wort nokka 'viel' angegeben. Auch die Variante tjuon-je findet sich bei Castrén in einem Personennamen: "pudar niser | tjuonje savua jeruh" "dein Vater ist | Fuchsfellmützen-Wirt" (256). ${ }^{1}$

Die im Wort 'Fuchs' erfolgten Lautwandel verstehen wir, wenn wir von einem urjurakischen Stamm *tăo(i)ne $+j \varepsilon$ ausgehen, wo das Element ${ }^{*} j \varepsilon$ ein Ableitungssuffix ist. Das kurze $i$-Element des Diphthongs (Triphthongs) hat sich mit dem ursprünglichen $* t$-Anlaut vereinigt und dessen Mouilliertheit herbeigeführt: $t i->t^{\prime}\left(t^{\prime}\right)$. Das $o$ der ersten Silbe lässt sich auf einen Diphthong oi zurückführen. Den Lautwandel $n>n$ im Wortinneren hat das an den konsonantischen Stamm getretene Ableitungssuffix ${ }^{*} j \varepsilon$ verursacht. Dies alles in Betracht ziehend können wir erklären, dass das urjurakische Wort *tioin $+j \varepsilon$, das auch eine Variante *liunje haben konnte, ohne phonetische Schwierigkeiten mit dem tawgyschen tunte'id.' und dem jenisseischen tudde, todde $(-d d-<$

\footnotetext{
1 Zum Diphthong uo vgl. Bud. tuone, tuảne 'róka [Fuchs]', Reg. tune 'id.'
} 
*-nt-) 'id.' gleichgesetzt werden kann. Die regelmässige Fortsetzung einer uralischen (finnisch-ugrischen) Konsonantenverbindung *-nt- ist im Jurakischen $-n$-.

Das jurakische Wort tōnnie und seine Formvarianten, wie anch tsoōn mit dem abgeschliffenen Ende, sind deutliche Nom.Sing.-Formen auch in Lehtisalos Texten: IIS side paridēn-

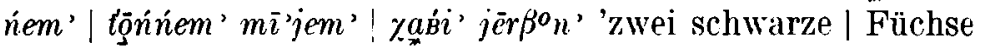
gab ich : den Fürsten der Ostjaken' (562); 0 riábi tsóñnèmtp.

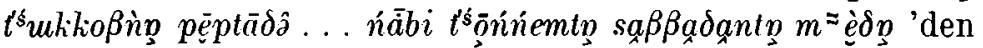
einen seiner Füchse wickelte er hier herum ... den anderen Fuchs nahm er als Mütze für sich' (22); PD ṕíśśe- $\beta=\grave{e} s o k k o ̄ r$

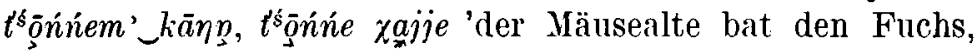
der Fuchs ging' (68) usw.

Dass (C) tôn' oder ton', (L) t'sóōn eigentlich Singularformen mit abgeschliffenem Ende sind, das beweist auch das Wort tōsa $\sim \bar{o} s$ 'Zobel', in dem wir den Abfall des Endvokals des zweisilbigen Stammes verfolgen können. Nach Castréns Wörterbuch ist $t \bar{o} s$ der Genitiv Sing. des Wortes $t_{\bar{o}}$ ' Zobel. In Lehtisalos Wörterbuch (S. 493) ist der Name des Zobels tōs, Sjo tō'. Die Gen.-Sing.-Form tōs in Castréns Wörterbuch können wir mit dem Nominativ (L) tōs identifizieren (und auch die Nominativform $\mathrm{C} t \bar{o}^{\prime}=\mathrm{L}$ Sjo $\left.t \bar{o}^{\prime}\right)$. Die Form $t \bar{o} s$ ist auch in Castréns Texten als Nominativ Sing. zu finden: $" j u$ tōs" "zehn Zobel» (292) "ju tōsa" 'id.' (ebd.). Die einsilbige Form tōs ist also durch den Abfall des Endrokals der zweisilbigen singularischen Grundform entstanden. Für die Form tōs können wir auch aus Lehtisalos Texten Beispiele anfüh-

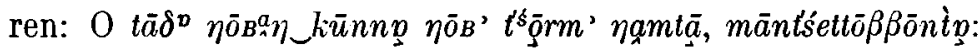
tôs tôs! 'Dann einmal hörte er einen Ruf, man hörte sagen: Zobel, Zobel!' (47). Der zweisilbige volle Stamm findet sich auch bei Lehtisalo in mit Possessiv- und Kasussuffixen versehenen Formen, wie in Zusammensetzungen: PD ṕiśse- $\beta=\grave{e}-$

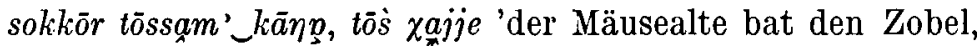
der Zobel ging' (68). In einer aus dem O-Dialekt aufgezeichneten "Heiligen Sage" lässt sich gut beobachten, dass dem gänzlichen Abfall des Endvokals im Wort 'Zobel' die Reduk-

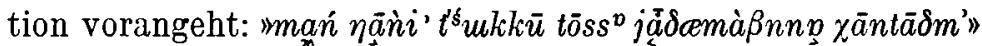
"ich wieder begebe mich längs der Spuren dieses Zobels» (47); 


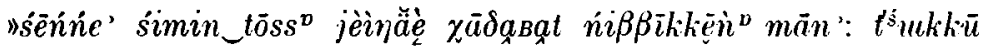

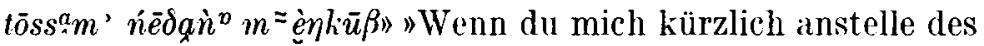
Zobels getötet hättest, hättest du wohl nicht gesagt: diesen Zobel nehme ich zu meinem Weibe» (51, vgl. 47). Der volle Stamm erscheint in der mit dem Possessivsuffix der 3. P. Sy. versehenen Lativform, die im Satz ein Nomen possessoris

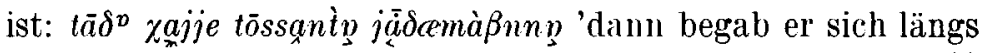

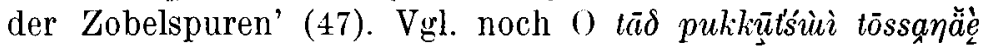

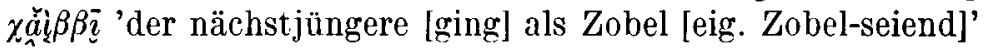
$(150$, vgl. Arch 175). In den Texten haben wir für die Pluralform des Wortes 'Zobel' keinen Beleg.

$\mathrm{R}$ e $\mathrm{n}$ t i e r. Von den Tiernamen wird allein der Name des zahmen Rentiers im Dual gebraucht (s.w.o. S. 224). Es taucht die Frage auf, ob dieser Tiername eine Pluralform hat. In Castréns Wörterbuch sehen wir die Formvariante $t y, t e, t \overline{\hat{o}}$. Aus den Texten können auch andere Nominativ- bzw. Stammformen belegt werden: $t i-(302), t e(67), t e h(67,257), t i h$ (243), tih (243), dieh (68), tie- $(65,132)$, tie- $(67), t \bar{e}(67), t \overline{-}-$ (69). Es fallen die Stämme teä- $(66,223)$, tea- $(205)$, deä(68), auf. Die letzteren dürften wohl durch den Abfall des $k$-Elements des Dualzeichens entstanden sein. (Aus den Texten besitzen wir keinen Beleg für das Wort $t \ddot{\partial}$.) In Lehtisalos Wörterbuch finden wir (S. 485) neben der Form $t \bar{\imath}$ auch

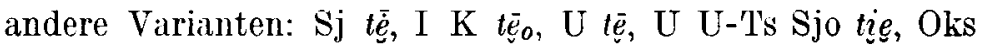

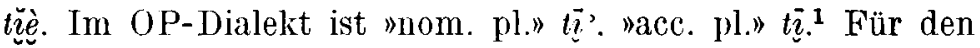
Namen des Rentiers habe ich in einer früheren Arbeit zahlreiche Belege aus den Texten ingeführt (ALH VII, 292293) und meiner Ansicht Ausdruck gegeben, dass in Castréns Texten das Element $v$ in den Nominativformen vom Typ tivaj zum Stamm gehört und $j$ das Pluralzeichen ist. (Anders P. Hajdú: NyK LXI, 23t.) Auffallend sind die Formen tevih bzw. tievin in den folgenden zwei Belegen: "tjikèdanda $\mid$ têvih änin garieda!" "Von hier | treibe die Rentiere wieder zum Lilnfen an!" (7), vgl. b. teami (20), c. tèmi teami (28); "tievin gānan | mungu tsalla tjäl» "Führe meine Rentiere | vor den Pfeilen in Schutz!) (10); vgl. b. teämin (22), c. temmi (29). Es ist

1 Vgl. jen. tia, Tawgy $t \bar{a}$, (Messerschmidt) $t a h$. 
nicht klar, ob das Element vih bzw. vin ein Possessivsuffix ist, oder ob das Element vi zum Stamm gehört. Das Wort tievin hat in der Variante a. auch die Formvariante tievï-nje und in dieser ist das Element - nje ein Possessivsuffix der 1. P. Du. (vgl. 219, 251, 258 usw.). Die Nominativform vom Typ tivaj kommt bei Castrén insgesamt viermal vor: "tivvaj $(\sim t \bar{v} v e j \sim t \bar{i} u v a j)$ okmi oì "Rentiere sind viel gekommen» (146); oka tîvaej $(\sim$ tivaj $)$ | salja mälon | siurulaptaeido' 'viele Rentiere an | der Spitze der Landzunge | kreisten sie ein' (191); $\bar{o} k a$ tîvoj, | satse ōka, | óleri atsekih $|j \bar{a} d a s|$ tänirnga 'viele Rentiere sind es, | sehr viele, | ein Bursche | zu Fuss | treibt' (254); "ōka jiliviāra, | ôka tìvaj | siu jān | tjārmadavaj" "Eure grosse Rentierherde, | viele Rentiere | in sieben Teile | sind sie ungeteilt» (257). (In der Endung daraj des Prädikats hat sich das Karitivsuffix mit dem passivischen Ableitungssuffix -vaj verbunden.) Auch der folgende Beleg ist zu beachten: "ōdibeä jādapts $\mid$ manj têviun | mioajeh!" »Faulbaumstab [Männername] | meine Rentiere I mag halten!» (235). ${ }^{1}$ Weder das Element $v$ noch das $i u$ ist eindeutig.

Interessant ist das folgende Beispiel: "side mahaheäna tẹv-ji-nje pōder'ah!" "Zwei Krummrücken | unsere [Du.] Rentiere schirre an!" (238). In der Form têr-ji-nje ist das Element $\beta$ kaum etwas anderes als der Laut im Wortinnern, und es kann für wahrscheinlich gehalten werden, dass die Velarisation des ursprünglichen palatalen Vokals in erster Linie eben dieses inlautende $\beta$ verursacht hat. Das Element $i i$ ist nicht eindeutig: es kann ein Pluralzeichen sein, aber auch ein im determinierenden Sinn gebrauchtes Konjunktivsuffix (vgl. FUF XXXVIII, 189-191, Anmerkung). An diese Möglichkeit müssen wir deshalb denken, weil auch das Konditionalsuffix si in determinierender Funktion auftritt in der folgenden Frage: "amga tëä-si-nje | ti jädalā?» "Was für Rentiere, | Rentiere sie transportieren?" (241). Setälä hat bekanntlich den nordsamojedischen Namen des Rentiers auch mit dem finnischen Wort teva, tevana gleichgesetzt: Renv.

1 Wir sehen die Elemente $v$ und $i u$ auch in einem nicht klaren Prädikat: "side hattariem | tienjewuongä-viun" "Zwei Graue kenne ich" (255). 
teva 'mas cervi alcis; männliches Elentier', tevana 'femina alcis; weibliches Elentier'. Diese Gleichsetzung darf man auch heute nicht ausser acht lassen. Vgl. noch Collinder: FUV 62.

Es ist nicht uninteressant, dass bei Castrén auch Nominativformen vom Typ teh $\sim$ teh $\sim$ dieh $\sim$ tih vorkommen, wo $h$ das Pluralzeichen sein kann: "tanjāngì teh | hartta njīdeh" "die dortigen Rentiere | sind ihre eigenen Kameraden" (257); tadhaua hajeh, | süjunda taevioi $i_{0} \mid$ jurmeän $\mid$ te $(\sim t \bar{e} \sim t e h)$ njuotā 'darauf ging er, | kam zu dem Kalb, | etwa hundert | Rentiere kommen hinterher' (67); stjuki dieh|njana waevonjuh" "Dieses Rentier | ist aber schlecht" (68); häjurtje tih | amzetih 'die zurückbleibenden Rentiere | würden sie fressen' (243). In diesen Belegen ist das Element $h$ in dem Namen des Rentiers mit dem Element $\rho$ gleichzusetzen, das wir aus einer Angabe Lehtisalos kennen: $\mathrm{Nj}$ tīo tiere sind dort sichtbar' (406). Da die Form teh, tih bei Castrén auch die Varianten $t \bar{e}^{-}$, $t \bar{t}^{-}$hat, kann angenommen werden, dass der Laut $\bar{e}, i$ aus dem Diphthong * $e i$ entstanden ist, und dass der bei Lehtisalo in velarisierter Form erscheinende Stamm tè-, tì- eigentlich ein Pluralstamm ist, der den Singularstamm aus dem Gebrauch verdrängt hat: O sarmik side tềm $i$ ' $\chi \bar{a} \delta a \beta \beta i$ 'der Wolf hatte zwei von meinen Rentieren getötet' (Mat 346). ${ }^{1}$

In Castréns und Lehtisalos Texten tritt der Name des Rentiers, der oft auch in der Bedeutung 'Rentierherde' vorkommt - mit, aber auch ohne Possessivsuffix - in der Funktion eines Subjekts, eines Objekts und eines Nomen possessoris im Satz auf. In allen diesen Funktionen kann Kehlkopfverschluss das Possessivsuffix ersetzen: a) T "mań

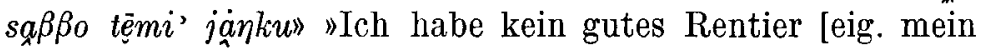
gutes Rentier existiert nicht]" (372); U $\operatorname{tin} \tan n \bar{a} j_{\bar{c}} \bar{a}^{\prime} m \bar{\imath} \delta^{\prime}$ 'meine Rentiere konnten nicht ans Ufer steigen' (Mat 359); tà ńắnnp tĩnnek $k \bar{a}$ ' 'im Sommer starben unsere Rentiere'

1 Das Element te-, ti- vertritt in solchen Belegen wie (C) tina edamah 'meine Rentiere liess ich frei' (302), jurmeän te 'etwa hundert Ren-

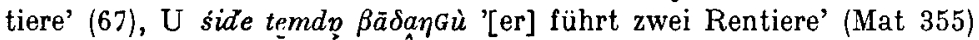
- wenn keine sekundäre Abkürzung erfolgt ist, - den Singularstamm. 
(ebd. 350). Am häufigsten tritt das Possessivsuffix der 3. Person als determinierendes Element an das Subjekt: (C) tìda oka aevioih 'Rentiere waren dort viel gewesen' (69); U tīoù'

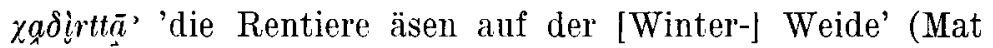

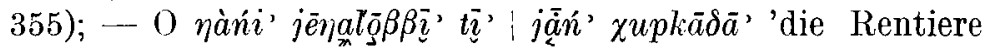
wieder, die gehangen hatten | fielen plumpsend zur Erde'

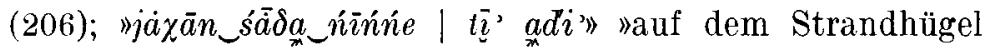
des Flusses / sind Rentiere sichtbar' (559); U tề' $n \bar{u}$ ' 'die Rentiere stehen' (Mat 359; ebd. mehrere Belege); -- b) U "ti t'áñnemsò $\beta n n p$ ma'lān!» "Sammle die Rentiere etwas!» (Mat 355); tīñi' máăttan_tānnàìn 'ich trieb meine Rentiere Zu dem Zelt' (Mat 346; ebd. mehrere Belege); O »nennp tì $\delta^{\partial}$

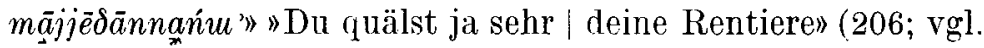
U 361); (C) »tadhaua hajeda' $\mid \bar{o} k a$ tĩde' $\mid$ tanaeida!» "Dann gehet, |

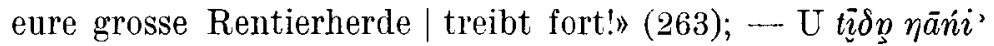

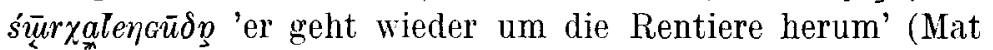

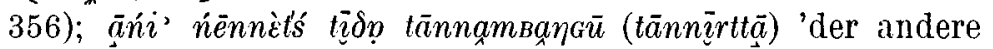
Mann treibt die Rentiere' (ebd. 358); BS tì $\delta \dot{o ̀ n} \_n \bar{u} l t t \bar{a}$ ' '[sie] brachten die Rentiere zum Stehen' (328; vgl. 292); U tī$\delta o \eta \_\eta \ddot{a} e ̂ t t i ̄ \delta u$ ' 'sie lassen die Rentiere frei' (Mat 358). c) In Fügungen, die das possessive Verhältnis bezeichnen, erscheinen beide Glieder im Nominativ: Arch side jurtıtil

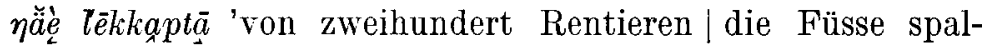
tete er' (174; vgl. jurt_tĩ nimne 'über hundert Rentiere') (ebd.). Am Ende des Nomen possessoris bzw. des Wortes mit Postposition erscheint der Kehlkopfverschluss anstatt des Possessivsuffixes: Arch tì' maśi' nimne 'über die Rücken der Rentiere' (174). In einem Beispiel nimmt das Nomen possessi das Possessivsuffix an, am Ende des Nomen possessoris weist der Kehlkopfverschluss auf das abgeschliffene

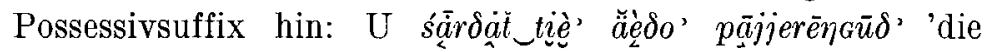
Füsse der Fahrrentiere [des Hirten] schwellen an' (Mat 361). Vgl. noch die hierhergehörigen Belege im Wb. S. 484. In mehreren Belegen ersetzt ein sekundärer Nasal den Kehlkopfverschluss: MB oppọi tī Kadaver eines Rentiers' (Mat 344). Doch kann dieses Element $n, \eta$ auch ein Lativsuffix sein. Es gibt ferner Belege dafür, dass das Wort für 'Rentier' in der Funktion eines No- 
men possessoris ein Lativsuffix und das Possessivsuffix der 3. P. annimmt: (C) teanda jinjem mueda '[sie] nahm die Zügel seines Rentiers' (35; vgl. 72); 一 O śi pīn' $\chi \bar{a} n n \bar{a} \delta \infty$ tênts $\chi \ddot{a} \ddot{e} \beta \beta \beta_{n} n$ ' 'der Siebenklafter Ostjake... führte seine Mutter hinaus neben sein Rentier' (90); T $\chi a n n n \bar{o}$ '

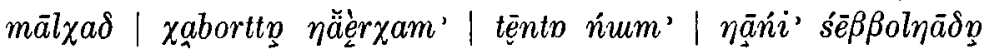
'vom Ende der Schlitten | um das Elchfussähnliche, | des Rentieres Kalb | wieder schlug er seine Arme' (373). - In den folgenden Belegen trägt das Nomen possessi das Posses-

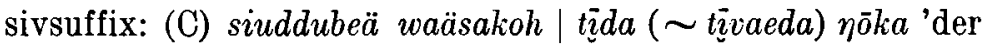
Riesenalte hat | viele Rentiere [Rentierpaare]' (179); $\mathrm{Ni}$

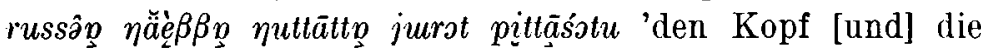
Hände des Russen steckte er in das Fett' (85-86). Im letzteren Beispiel nimmt nur das zweite Nomen possessi das Possessivsuffix an. - Im postpositionalen Konstruktionen erscheint die pluralische Grundform allein bzw. mit Kehlkopfverschluss am Ende als das Wort mit Postposition: Arch

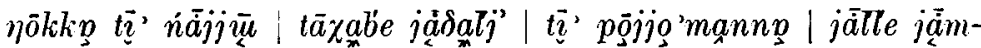

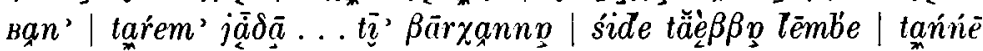
$\beta \bar{a} n n a \hat{\beta} e \chi e^{\prime}$ ' 'auf die grosse Rentierherde zu | begab er sich dann zu wandern / unter den Rentieren / den Tag lang geht er so ! . . Am Rande der Herde | zwei Breitschwänze liegen da' (174); vgl. MB ti' pōjjờmanno 'unter den Zugrentieren' (Mat 343), (C) teh poimana | äedliornā 'mitten in den Rentieren | fahren sie' (66). Die Form teh ist identisch mit der sekundären pluralischen Grundform, die durch Ausfall des ursprünglichen inlautenden Konsonanten entstandeu ist. Der Vokal der ursprünglichen ersten Silbe dürfte ein $e$ sein; vgl. z.B. die Dualformen bei Castrén.

Pluralformen mit $\bar{o} \sim \bar{u}(o \sim u)$ a m Ende.

S c hl lit te n. Die Stämme (C) hana-, (han-), (Wb. 155

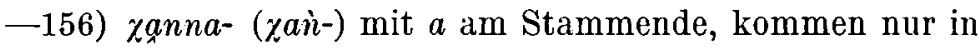
singularischer Bedeutung vor, die sekundären Stämme $\chi a n n n o ̄$, $\chi a n n \bar{u}$ werden aber teils in singularischer, teils in pluralischer Bedeutung gebraucht: (C) njär tidekou | hana wādkua'ah 'meine drei Mutterbrüder | führen meinen Schlitten' (282); handa njin $d j \bar{i}$ '[er] setzte sich in seinen Schlitten' (68); PD xànnáx' pōdermi 'er spannte den Schlitten an' (Mat 


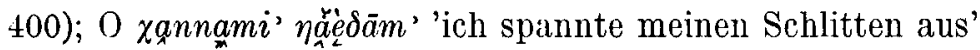

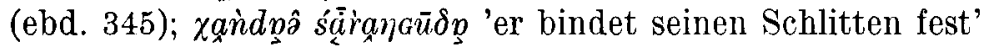
(ebd. 356). - Im folgenden Beleg sehen wir das Wort 'Schlitten' als $a$ - und $\bar{o}, \bar{u}$-Stamm gleichermassen in singularischer

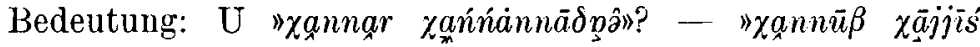

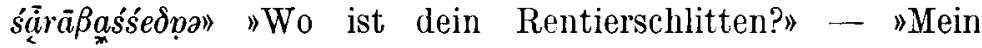

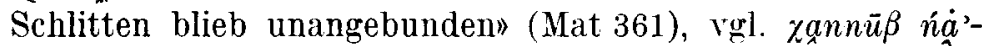
mām' 'ich nahm meinen Schlitten' (ebd. 343; vgl. 285, 243)

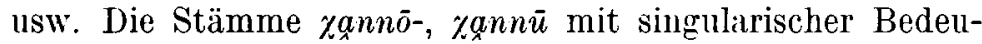
tung sind ebenso Stämme mit dem Ableitungssuffix *je(i) wie

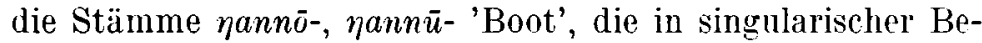
deutung vorkommen (vgl. Abl. Suff. 55). In einer anderen Gruppe der Belege mit pluralischer Bedeutung aber beweist das Pluralzeichen $i$, das in einem Beleg Castréns sogar zweimal erscheint, dass das Pluralzeichen mit dem Endvokal $\bar{o}, \bar{u}$ des Singularstammes verschmolzen ist, weshalb die Singularund Pluralstämme formal zusimmengefallen sind: (C) taeri jāna | side meäh. | njündje njā $\mid$ sidem boh | hanno-i-dimuevae | jiris $\bar{u}$ | hanno-i-tji nje àmdavae 'an einem seitwärtigen Platze | sind zwei Zelte. | Mit seinem Sohn | zwei Jahre | stellten sie ihre Schlitten | nebeneinander, | sie setzen sich in die Schlit-

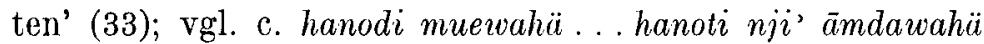
(55). Die Entsprechung des Pluralstammes hanno- $i$ - erkennen wir in einem aus dem $\mathrm{Nj}$-Dialekt aufgezeichneten Beleg:

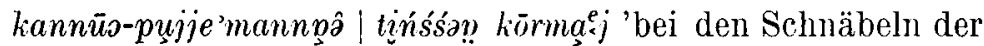
Schlitten $\mid$ prüfte es das Lasso' (416). Die Singularform $k \grave{a} n$ und die Pluralform $\chi_{x}$ nnō' sind im Gebrauch deutlich abweichend in einem Beleg ans dem O-Dialekt: "yannō"' mãl-

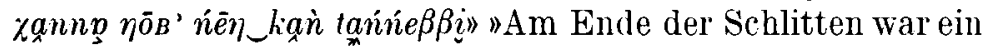
Frauenschlitten" (441). Es ist aber auch möglich, dass in diesem und dem folgenden Beleg das abgeschliffene Possessivsuffix der 3 . P. die pluralische Bedeutung angibt: MS $n \dot{n} \bar{a} \beta^{\prime} i$

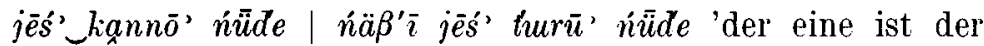
Jüngste der Eisenschlitten, der andere ist der Jüngste der Eisentreibstangen' (259). ${ }^{1}$

${ }^{1}$ Die Form jēś ist keine "acc. pl.»-Form (vgl. Wb S. 116), sondern der Nominativ Sing. mit abgeschliffenem Ende des Stoffnamens. Da Castréns das Pluralzeichen $i$ enthaltende Belege mit pluralischer 
Z e 1 t. Dieses Wort kommt in den jurakischen 'Texten sehr häufig vor: (C) mea', (Wb 266---268) tundrajurakisch

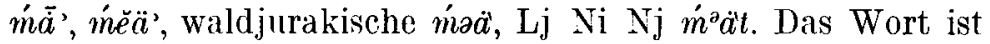
in allen samojedischen Sprachen zu finden. Im ursamojedischen zweisilbigen Wort stand ein *-t-im Inlaut. Zn den aus den verschiedenen jurakischen Stammrarianten stammenden Formen vgl. ALH VII, 273-277. Für den zweisilbigen Singularstamm besitzen wir sehr wenige Belege: (C) meata-n taevioih 'zu dem Zelte kam er' (5; vgl. 182); piritse jē ninje ! meadada adih 'auf der hohen Stelle liegende | Zelte sind sichtbar' (225; in diesem Beispiel fällt die Pluralform $j \bar{e}$ des Wortes $j \bar{a}$ Erde, Stelle auf); siu maro deata | meädado mallié 'sieben geizige Wirte | brachen ihre Zelte ab' (65). - Für die pluralische Grundform meädo, $\dot{m} \dot{a} \delta \bar{o} \sim \dot{m} \bar{a} \delta \bar{u}$ gibt es viele Belege in den Texten; diese ist aus der Verbindung des zweisilbigen *a-Stammes und des Pluralzeichens $i$ entstanden. ${ }^{1}$ Die pluralische Grundform erscheint allein und viel häufiger mit Possessivsuffixen versehen in der Funktion eines Subjekts, eines Objekts und eines Nomen possessoris im Satz: a) T máāonni_jankku 'meine Zelte sind nicht vorhanden' (377); (C) opoj meadodih | hajuvioih 'nur ihre [Du.] Zelte | blieben' (214); nieuhī meadoda | njār meätah | sinindo padlih 'seine alten Zelte | drei Zelte, | in alter Weise stehen' (17); Kan

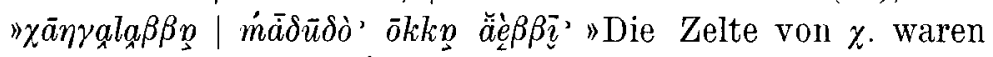

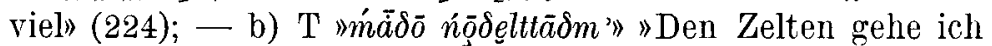

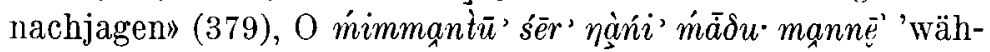
rend sie gehen, sahen sie wieder Zelte' (466, vgl. 447, 452);

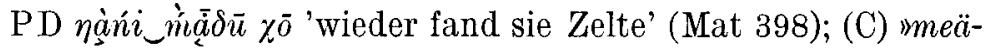
dona ko'odi!» "Bringet [Du.] die [eig. unsere] Zelte!» (186);

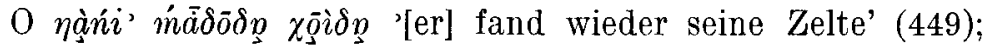

Bedeutung damals meiner Aufmerksamkeit entgangen waren, habe ich die pluralische Bedeutung der Stämme mit auslautendem $o, \bar{u}$ in allen Fällen als das Ergebnis der Differenzierung gedeutet (vgl. ALH VII, 280-281).

1 Der Kehlkopfverschluss am Ende der Pluralstämme vertritt das Element ${ }^{*} t$ des Possessivsuffixes. In Formen dieses Typs kann der Kehlkopfverschluss im Auslaut nicht das Ableitungssuffix $* \beta$ oder ${ }^{*} j$ ersetzen; vgl. ALH VII, 279-281. 


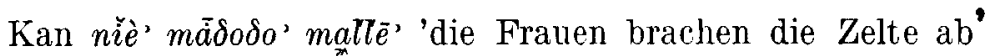
(231); - c) In der Funktion eines Nomen possessoris (ein Wort mit Postposition) erscheint der Pluralstamm bei Castrón ohne Kehlkopfverschluss, bei Lehtisalo in der Regel mit Kehlkopfverschluss: (C) meädo juorkkan taevioih 'in dem Halbkreis der Zelte langte er an' (220); ōk meädo njājū $\eta$ gajeh 'er ging auf viele Zelte zu' (142); - O t'sikkì máä

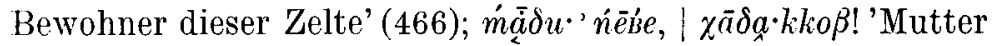
der Zelte, | meine Grossmutter!' (508); MS ḿả $\delta \bar{o}^{\circ}$ nónnnią ${ }_{G} \bar{a}$ ' $m \tilde{\imath} \delta$ ' '[sie] liessen sich herab | zur Türseite der Zelte' (255).

$\mathrm{F}$ i s c h. Es war eigentlich ein a-Stamm anch im Jurakischen, ist aber später in die Kategorie der $\ddot{a}$-Stämme übergegangen (vgl. FUF XXXVIII, 141). Das im allgemeinen als Kollektiv gebrauchte Wort hat nach vereinzelten Belegen auch eine vom Stamm $\chi a ̈ l l e$ stammende Pluralform: $O$ "mań

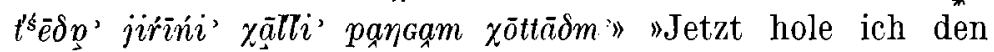
Fischschwarm meines Grossvaters" (26). - In der Beschreibung des Fischens mit dem Zugnetz (Mat 370-372) finden sich vier Belege für den Gebrauch des Wortes $\chi \bar{a}$ llte als Kollektiv; in zwei von diesen vertritt der Kehlkopfverschluss das abgeschliffene Possessivsuffix bei der Funktion des Wortes als Subjekt bzw. als unbezeichnetes Objekt. In demselben Text gibt es einen Beley für die pluralische Grundform gallu und zwei Belege für den Pluralstamm $\chi a ̄ l l u-$. Diese Formen sind die mit dem Pluralzeichen $i$ versehenen Formen des $a$-Stammes ${ }^{*} k \bar{a} l a\left({ }^{*} k \bar{a} l a+i>a_{a} \bar{l} l u \sim \chi \bar{a} l l u-\right): ~ " \bar{u} s \bar{a} t$

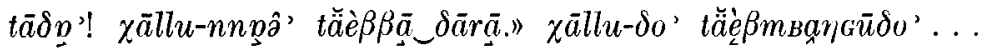

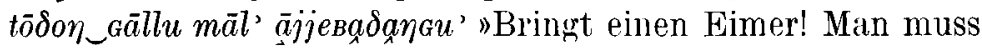
die Fische herbringen." 'Sie fangen an, die Fische zu tragen ... Jeder isst den Fisch roh' (371). Diesen Phralformen aāllu $\sim$ $\chi \bar{a} l l u$ - lässt sich die in Castrúns Texten vorhandene Form haloh gleichstellen: siuddubeäh | tij nar hōloh | jilinjahanda | namsetida 'der Riese | so viel Fische | lebendig | isst' (174). Die Form hāloh lässt sich auf die pluralische Grundform *hāloi < ${ }^{*} k a \bar{l} l a+i$ zurückführen. Vgl. Gr. § 242: "Gen. Plur. hâl' oder hâlo'." Im Beispiel Castréns hâlo' (und hâl') ersetzt der Kehlkopfverschluss das determierende Possessivsuffix der 3. P., vgl. U $\chi \bar{a} l l u-\delta 0^{2}$. 
Der Plural einiger einsilbiger Wörter

K a m e r a d. Nach der Grammatik lautet die Gen. Plur. -Form des Wortes ńa Kamerad $n^{\prime} \bar{\imath}$ (§ 242). Im Wb (S. 299) stammen die Pluralformen des Wortes ńä waldjur. $n^{\triangleright} \dot{\dot{a}}$ aus den Stämmen $n^{\prime} \bar{\imath}$ und $n \bar{\imath}$-. In Castréns waldjurakischen Aufzeichnungen (Mat 282) ist der Pluralstamm nie: nien 'meine Kameraden' (vgl. njen ebd. 301), niemi 'unsere [Du.] Kameraden', niena 'unsere Kameraden', nieda 'seine Kameraden'. In den Texten kommt der Pluralstamm in allen Belegen mit dem Possessivsuffix als Subjekt, Objekt und Nomen possessoris vor: a) (C) "siu jī $d m$ buo $(\sim b o) \mid n j \bar{i} n a(\sim n \bar{i} n a)$ kajets" "Vor siebzig Jalıren | begaben sich meine Kameraden fort" (94); "njīda mädadtsumah| waraukōdamda" »Deine Kameraden schlagen um [Birken] | zu Spänen für dich" (273-274); -

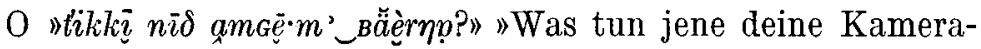

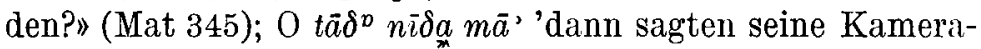
den' (30);-- b) T ńin niăllkkäjjen 'ich nahm meine Kameraden

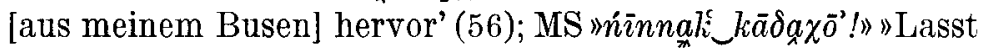
uns unsere Kameraden erschlagen!" (77); "amaé ni $\bar{i} i{ }^{\prime}$ ' ni$d^{\prime} i \eta \_G \bar{a} \delta \eta^{\prime}$ ?" "Warum erschlugt ihr nicht eure Kameraden?"

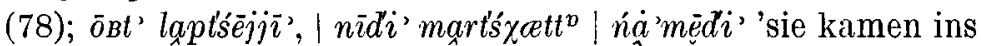
Handgemenge, | ergriffen | einander bei den Schultern' (257);

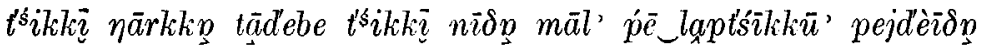
'der grosse Zauberer klopfte alle diese seine Kameraden mit

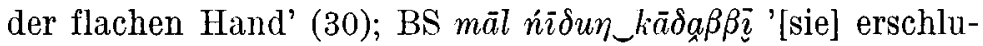
gen alle ihre Kameraden' (334, vgl. PD 396); - c) O stàjlkkùi

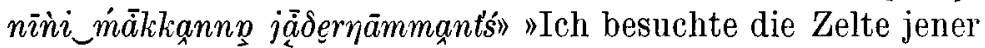

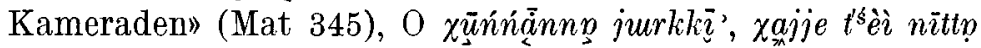
jāoßmi' mümńe 'am Morgen stand er auf, begab sich längs der gestrigen Spuren seiner Brüder' (47-48; doppeltes Possessivverhältnis, am Ende des zweiten pluralischen Nomen possessoris Kehlkopfverschluss); $t \bar{\alpha} \delta^{v} t^{\prime}{ }^{\prime} i k k \bar{\imath} n \bar{\imath} \delta \underline{\underline{z}} n \bar{\imath} t t \bar{u}{ }^{\prime} \beta \bar{a} \delta \bar{a} \chi \grave{a}^{\prime}$

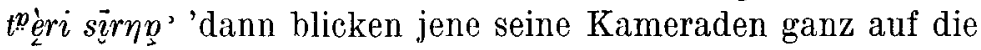

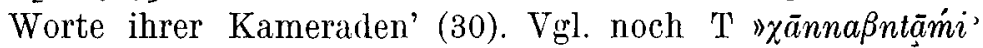

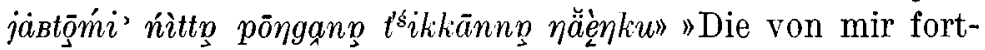
gebrachte Gans ist da unter ihren Kameraden» (Mat 419).

Aus dem Wechsel $n-\sim n$ - im Pluralstamm können wir den Schluss ziehen, dass das anlautende $n^{\prime}$ - im singularischen Tort $n \dot{a}$ ein sekundärer Laut ist. Die Singularform lässt sich 
auf ein urjurakisches Wort *niei $\sim *_{n}^{*}$ ăi zurückführen. Das erste kurze $\check{i}$-Element des Triphthongs ist mit dem $n$-Anlaut verschmolzen, sein zweites Element wiederum ist die Fortsetzung des ursprünglichen inlautenden $*_{-j-:}^{*} n \check{i} \dot{a} i i_{i}>n \dot{a}$. Die Doppelform des Pluralstammes kann damit erklärt werden, dass aus der Verbindung ${ }^{*} n e i \sim{ }^{*} n \dot{a} i$ mit dem Pluralzeichen $i$ der Stamm $n \bar{i}$ - entstanden ist, der Stamm $n^{\prime} \overline{-}$ aber kann auf

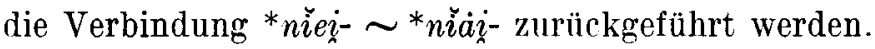

Das Wort mit der Bedeutung 'B a u m' war in der uralischen Grundsprache zweisilbig. Hierauf deutet im Selkupischen (Mat 74) Tsch OO puo, B Tas Kar puo- und im Kamassischen (D-J) p'å $i-i{ }^{\prime}$ 'Wald (eig. Bäume)'. Vor dem Pluralzeichen erscheint der Singularstamm $p$ ‘ $a ̊ x$. In einigen waldjurakischen Angaben sehen wir den Stamm $\dot{p} \ddot{e} \dot{a}^{2}$, z.B. $\mathrm{P}$ $\dot{p}^{\prime} \bar{a}^{\circ} k k \bar{u} \_t \bar{o}$ 'See in der Quellengegend des Purs.' Bei Castrén ist das Wort für Baum pea, bei Lehtisalo (Wb 371) ṕà, $\dot{p} \ddot{e} \grave{a}$. Pluralformen: O $p \bar{\imath}, \mathrm{Nj}$ pé vacc. pl.", M $\dot{p} \ddot{e} \dot{a}^{\prime}$ "nom. pl." In der ursprünglichen ersten Silbe stand ein velarer Vokal in der uralischen und der finnisch-ugrischen Grundsprache, wahrscheinlich $u$, der nicht nur im Finnischen bewahrt wurde, sondern auch in der selkupischen Form B Jel Tas Kar puu. Der ursprüngliche kurze Vokal wurde durch den Ausfall des inlautenden Lautes lang. Der ursprüngliche ursamojedische Inlaut dürfte ${ }^{*}-\gamma$ - gewesen sein; dieses hat — zumindest im Jurakischen - auch eine Fortsetzung *-j-. Das urjurakische Wort war wohl *puj(e). Das Offenerwerden des einsilbigen Wortes hat im Jurakischen (vgl. noch jen. pä $\sim f \bar{e}$ ) das $*_{-j}$ - im Inlaut herbeigeführt: nach dem Abfall des Endvokals hat sich der ursprüngliche Inlaut $*_{-j}-\sim *_{-} i$ - zu einem Diphthong vereinigt mit dem Vokal bzw. mit dem Diphthong (vom Typ $i \dot{a}$ ) der ersten Silbe. Wie auch in anderen Fällen verschmolz das

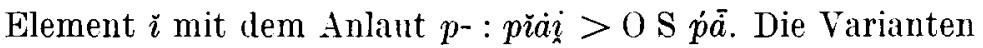
des Diphthongs existieren auch heute noch in mehreren Dialekten. - Die pluralische Grundform lässt sich auf die Verbindung des einen palatalen Vokal (Diphthong) enthaltenden Singularstammes und des Pluralzeichens $i$ zurückführen:

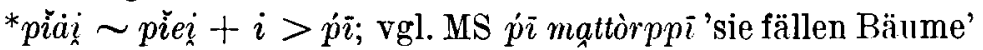
(77). In den Texten erscheint nath rereinzelten Belegen der Pluralstamm mit Possessirsuffixen versehon als Subjekt und 


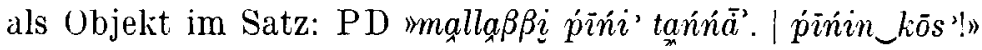
"Von mir gesammelte Holz gibt es. | Meine Hölzer hole!»

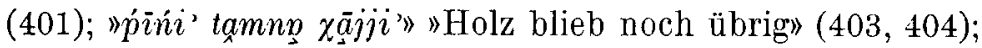

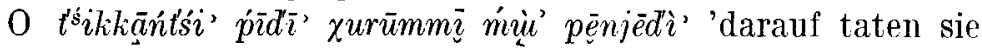
[Du.] das Holz auf den Warenschlitten' (462).

L a n d, E r d e. Wie das Verhältnis (Wb 86) 0 jä 'Land, Erde, Ort, Stelle, Platz' Nj $j \ddot{e} \grave{a}$ 'id.' und die nacc. pl.»-Form $j \bar{o}$ zueinander gedeutet werden kann, lässt sich mangels Belege schwer beantworten. Paasonen (Beitr. 217, 266) hat das jurakische Wort $j a$ mit dem selkupischen $c ̌ u$, $t^{\prime} u$ 'Sand, Erde, Lehm' gleichgesetzt. Dieses Wort existiert auch in Zusammensetzungen, z.B. čuuje-gum 'Samojede' (vgl. Mat 98), wo das erste Glied ein $-j$-Element enthält. Den ursprünglichen velaren Vokal hat wohl die Form $j \bar{g}$ bewahrt. Die mit dem Possessivsuffix der 3. P. Sg. versehene Form jō $\delta \dot{a}$ kommt als Subjekt des Satzes bei Lehtisalo vor: O $t \bar{a} \delta^{p}$

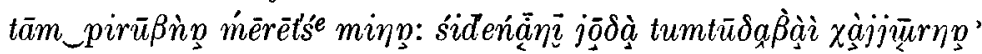
'dann geht sie so schnell, dass sie auf keiner der beiden Seiten das Land kennt | das hinter ihr bleibt [eig. die Länder blieben unbekannt]' (158; das Prädikat ist eine Plur.-Form). Vgl. noch $\mathrm{Nj} \eta \bar{e}^{-\dot{n}^{\prime} \dot{\imath}} j \bar{g}$ manni $\hat{\eta}^{\eta}$ ' $\eta \bar{a} t$ 'seltsame Länder sah ich' (Wb). ${ }^{1}$

Auch das Verhältnis zwischen (C) $s a^{\prime}$ Zugriemen, (Wb 401)

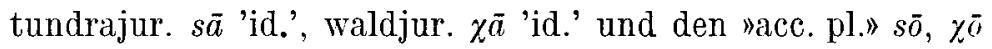
ist unklar. Aus den Texten besitze ich lediglich zwei Belege für den Stamm sō- und eigentlich gibt in beiden Belegen das Possessivsuffix des Plurals die pluralische Bedeutung an: (C) tjāt jalikou | sōó wānuuvuih 'meine vier Hellen | haben

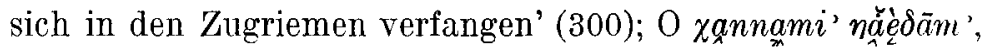

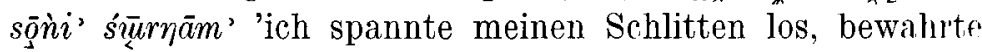
die Zügel auf' (Mat 345). Zu beachten sind auch die Belege aus dem Jenisseischen: B so 'Halfter', Ch sa 'id.' Diese sind zweifellos Nominativ-Singular-Formen.

Auf Grund der oben behandelten Daten können wir feststellen, dass das Element ${ }^{*} j \varepsilon(i)$, das im Prädikat auf das

1 Bei Castrén fällt — wie oben erwähnt — die Singularform $j \bar{e}$ auf (225). Diese Form hat sich wahrscheinlich aus der Form *jai $\sim$ *jei entwickelt, und in dieser wird das Element $i \underset{\alpha}{i}$ die Fortsetzung des ursprünglichen Inlautes sein. 
pluralische (und ziemlich oft dualische) Objekt, in der possessiven Deklination auf den pluralischen Besitz hinweist, mit dem Element $*_{j \varepsilon(i)}$ identisch ist, das in der pluralischen Grundform der juraksamojedischen Nomina die Pluralität bezeichnet. Die Erscheinungsform der pluralischen Grundform hängt vom Endvokal des Singularstammes ab, bzw. davon, ob das Pluralzeichen an den vollen vokalischen Stamm tritt, oder an den einsilbigen konsonantischen Stamm. Einige einsilbige "Pluralformen" sind mit der Nom.-Sing.-Form, deren Endvokal abgeschliffen ist, identisch. Die juraksamojedische pluralische Grundform kann man mit der lappischen pluralischen Grundform gleichsetzen, die der lappische Gen. Plur. vertritt (vgl. Ravila, a.a.O. 72-74). Im Jurakischen wird die pluralische Grundform sowohl als Subjekt und Objekt als anch in der Funktion des Nomen possessoris in einer possessiven Fügung gebraucht, zum Teil - nach geringen Belegen - allein, zunächst aber - als eine im Sonderleben der juraksamojedischen Sprache entwickelte Eigentümlichkeit - mit Possessivsuffixen versehen. Die Possessivsuffixe haben im Jurakischen auch eine sehr ausgedehnte determinierende Funktion (vgl. ALH VII, 48-50, 65-66). Der Kehlkopfverschluss, der statt des $t$-Elements des Possessivsuffixes erscheint, tritt in allen drei Funktionen a u f, am häufigsten aber am Ende des Nomen possessoris. Die "Regel» kann also nicht aufrechterhalten werden, wonach der Kehlkopfverschluss das Charakteristikum des Genitiv-Plurals sei, bzw. dass der Akkusativ-Plural immer ohne Kehlkopfverschluss erscheinen soll. Der Unterschied zwischen dem Febrauch der lappischen pluralischen Grundform und der jurakischen Grundform ist, dass die pluralische Grundform im Jurakischen viel häufiger mit Possessivsuffixen erscheint als ohne sie. Und gerade die Tatsache, dass die pluralische Grundform allein in drei Funktionen - als Subjekt, Objekt und Nomen possessoris - gebraucht wird, lässt die Annahme zu, dass der ursprünglichere Zustand beim Gebrauch der pluralischen Grundform in der juraksamojedischen Sprache bewahrt worden ist. 